\title{
Immune-related genes of the larval Holotrichia parallela in response to entomopathogenic nematodes Heterorhabditis beicherriana LF
}

Ertao Li ${ }^{1}$, Jianhui Qin ${ }^{1}$, Honglin Feng ${ }^{2}$, Jinqiao Li ${ }^{1}$, Xiaofeng Li', Innocent Nyamwasa', Yazhong Cao ${ }^{1}$, Weibin Ruan ${ }^{3}$, Kebin $\mathrm{Li}^{1 *}$ and Jiao $\mathrm{Yin}^{1 *} \mathrm{D}$

\begin{abstract}
Background: Entomopathogenic nematodes (EPNs) emerge as compatible alternatives to conventional insecticides in controlling Holotrichia parallela larvae (Coleoptera: Scarabaeidae). However, the immune responses of H. parallela against EPNs infection remain unclear.

Results: In present research, RNA-Seq was firstly performed. A total of 89,427 and 85,741 unigenes were achieved from the midgut of $\mathrm{H}$. parallela larvae treated with Heterorhabditis beicherriana LF for 24 and $72 \mathrm{~h}$, respectively; 2545 and 3156 unigenes were differentially regulated, respectively. Among those differentially expressed genes (DEGs), 74 were identified potentially related to the immune response. Notably, some immune-related genes, such as peptidoglycan recognition protein SC1 (PGRP-SC1), pro-phenoloxidase activating enzyme-I (PPAE-I) and glutathione s-transferase (GST), were induced at both treatment points. Bioinformatics analysis showed that PGRP-SC1, PPAE-I and GST were all involved in anti-parasitic immune process. Quantitative real-time PCR (qRT-PCR) results showed that the three immune-related genes were expressed in all developmental stages; PGRP-SC1 and PPAE-I had higher expressions in midgut and fat body, respectively, while GST exhibited high expression in both of them. Moreover, in vivo silencing of them resulted in increased susceptibility of $H$. parallela larvae to $H$. beicherriana LF.

Conclusion: These results suggest that $H$. parallela PGRP-SC1, PPAE-I and GST are involved in the immune responses to resist $\mathrm{H}$. beicherriana LF infection. This study provides the first comprehensive transcriptome resource of $H$. parallela exposure to nematode challenge that will help to support further comparative studies on host-EPN interactions.
\end{abstract}

Keywords: Entomopathogenic nematode, Holotrichia parallela, Immune response

\footnotetext{
*Correspondence: kbli@ippcaas.cn; ajiaozi@163.com

${ }^{1}$ State Key Laboratory for Biology of Plant Diseases and Insect Pests, Institute

of Plant Protection, Chinese Academy of Agricultural Sciences,

Yuanmingyuan West Road, Beijing 100193, China

Full list of author information is available at the end of the article
}

(c) The Author(s). 2021 Open Access This article is licensed under a Creative Commons Attribution 4.0 International License, which permits use, sharing, adaptation, distribution and reproduction in any medium or format, as long as you give appropriate credit to the original author(s) and the source, provide a link to the Creative Commons licence, and indicate if changes were made. The images or other third party material in this article are included in the article's Creative Commons licence, unless indicated otherwise in a credit line to the material. If material is not included in the article's Creative Commons licence and your intended use is not permitted by statutory regulation or exceeds the permitted use, you will need to obtain permission directly from the copyright holder. To view a copy of this licence, visit http://creativecommons.org/licenses/by/4.0/ The Creative Commons Public Domain Dedication waiver (http://creativecommons.org/publicdomain/zero/1.0/) applies to the data made available in this article, unless otherwise stated in a credit line to the data. 


\section{Background}

The dark black chafer (Holotrichia parallela Motschulsky) is a polyphagous pest that impacts many major crops, pastures and herbs in East Asia, particularly in China [1-3]. The larvae, white grubs, live in soil and prefer to feed on plant roots, causing an average economic loss of more than $15 \%$ per year [4]; in serious cases, the losses may exceed $50 \%$ [5]. In recent years, the implementation of agricultural measures, such as no-tillage and shallow tillage systems, straw return, has created unique conditions for the survival and quantity of white grubs [6,7]. The application of chemical insecticides has been widely used as an effective measure in white grub management but resulted in soil and groundwater pollution $[8,9]$.

Entomopathogenic nematodes (EPNs), including Steinernematidae and Heterorhabditidae, are regarded as potential biological control agents to control a wide range of insect pests, especially those that occur in soil [10]. Similar to predators, the infective juveniles (IJs) of EPNs possess chemoreceptors that can actively search for susceptible hosts living in the soil $[11,12]$. Once IJs have captured susceptible hosts, they will enter the host through their natural body openings such as stoma, valve and anus, eventually reaching the host's haemocoel and gut region, and then the IJs release the symbiotic bacteria that secrete proteases, protoxins and other insecticidal substances complex to establish infection [13]. More importantly, EPNs are highly virulent, killing the pest quickly, meanwhile they are safe to vertebrates and plants [14]. In 1929, EPNs were first discovered as the parasites of Japanese beetle (Popillia japonica) in New Jersey [15] and produced a high mortality to white grubs [16]. To date, approximately seven EPN species, including Steinernema scarabaei, Steinernema glaseri, Heterorhabditis bacteriophora H06, Heterorhabditis spp., Steinernema longicaudum X-7, Heterorhabditis indica LN2 and Heterorhabditis beicherriana, have shown potential control abilities for $P$. japonica, masked chafers (Cyclocephala borealis Arrow), Holotrichia oblita and $H$. parallela [7, 17-21]. However, the pathogenicity of nematodes is unstable in practical applications, and the control effect is unsatisfactory [22, 23]. The deadliest cause was that white grubs possess a strong immune system [24], which may effectively resist nematodes to establish infection [25]. Specifically, white grubs can recognize EPNs through the sensitive immune system and can encapsulate or melanize invading nematodes [26-28].

Generally, the immune system of insects will be activated after infection by parasites or pathogens. First, pattern recognition proteins (PRPs) primarily recognize and tag invaders [29-32]. Then, PRPs rely on the cascade reaction of serine proteases (SPs) to continuously expand signals and eventually transmit the signals to the nucleus [33]. Finally, antimicrobial peptides (AMPs) were used to perform phagocytosis, nodulation and encapsulation depending on the invader [34, 35], and other immunerelated genes, including GSTs, heat shock protein (HSPs) and superoxide dismutase (SOD), were also involved in the anti-parasitic immune response [24].

Recently, mRNA sequencing (RNA-Seq or transcriptome sequencing) has been widely applied to identify immune-related genes and study the molecular basis of host-bacterial and/or host-parasite interactions. Moreover, this method also provides comprehensive insight into the immune gene repertoire of non-model insects, and this technology has become a reliable method to identify and analyze differentially expressed genes (DEGs) as targets for pest control [36, 37]. For instance, transcriptome sequencing results of Drosophila response to H. bacteriophora $\mathrm{H} 222$ infection indicated that most of the strongly induced genes were implicated in immune responses [38]; Many immune-related genes (such as PRPs, immune-related signal transduction proteins, AMPs and cellular response proteins) were induced in the white-spotted flower chafer (Protaetia brevitarsis seulensis Kolbe) with Escherichia coli and Saccharomyces cerevisiae challenge [24]; Heliothis virescens response to $H$. bacteriophora infection results indicated that insect immune response genes were induced upon nematode invasion, but the majority of these genes were suppressed after the release of symbiotic bacteria by the nematode [39]. However, the molecular immune mechanism of $H$. parallela against EPNs infection has not been elucidated.

In this study, we primarily generated the first comprehensive transcriptome resource regarding $H$. parallela larvae in response to the nematode infection and screened the DEGs associated with immune defence. Then, we predicted the roles of three key immunerelated genes in anti-parasite immune processes based on bioinformatics analysis. After that, we performed qRT-PCR to investigate the spatiotemporal expression patterns of these key immune-related genes. Finally, we silenced these immune-related genes to test their effects on the susceptibility of $H$. parallela larvae to $H$. beicherriana LF.

\section{Results}

Transcriptome overview of Holotrichia parallela midgut

Through sequencing, a total of 89,427 and 85,741 unigenes were generated from the midgut samples of $H$. parallela larvae treated with the nematode $H$. beicherriana LF for 24 and $72 \mathrm{~h}$, respectively. The specific statistics of transcriptomes are shown in Table 1.

After treating the larvae of $H$. parallela with nematodes for $24 \mathrm{~h}, 2545$ genes were significantly differentially expressed compared to the sterile water treatment, among which 925 were upregulated and 1620 were 
Table 1 Summary statistics of transcriptomes

\begin{tabular}{lllll}
\hline Summary & Hp-CK1 & Hp-LF1 & Hp-CK3 & Hp-LF3 \\
\hline Raw reads number & $47,126,795$ & $45,510,292$ & $45,690,800$ & $46,603,740$ \\
Raw bases number & $7,049,508,850$ & $6,826,543,800$ & $6,816,176,000$ & $7,018,329,600$ \\
Clean reads number & $46,156,622$ & $44,287,283$ & $44,894,961$ & $45,457,525$ \\
Clean bases number & $6,885,817,500$ & $6,643,092,450$ & $6,847,377,850$ & $6,818,628,750$ \\
Clean Q30 bases rate (\%) & 95.13 & 94.92 & 95.58 & 35.50 \\
Percen GC of trinity/ unigenes (\%) & $35.77 / 35.28$ & $35.98 / 35.45$ & $35.47 / 35.34$ & $35.85 / 35.42$ \\
Count of trinity/ unigenes & $156,263 / 70976$ & $175,496 / 89427$ & $167,584 / 79571$ & $176,586 / 85741$ \\
Mean length of trinity/ unigenes & $890.87 / 771.14$ & $928.46 / 756.53$ & $945.18 / 799.56$ & $899.75 / 786.42$ \\
N50 of trinity/ unigenes & $1542 / 1200$ & $1598 / 1495$ & $1613 / 1299$ & $1687 / 1428$ \\
\hline
\end{tabular}

Note: Hp: Holotrichia parallela; LF1: postexposure to $\mathrm{H}$. beicherriana LF for $24 \mathrm{~h}$; LF3: postexposure to $\mathrm{H}$. beicherriana LF for $72 \mathrm{~h}$. The data are presented as two biological replicates. Clean Q30 bases rate is identified as the proportion of bases with a mass value greater than 30 (error rate less than $0.1 \%$ ) in the total sequence after filtration. N50 is identified as the sequence length of the shorted contig at $50 \%$ of the total genome length

downregulated. At $72 \mathrm{~h}$ postexposing, 3156 genes were significantly differentially expressed, among which 891 were upregulated and 2265 were downregulated (Fig. 1a). In addition, we found that 159 genes were upregulated and 333 genes were downregulated at both time- poins; 214 genes were downregulated at $24 \mathrm{~h}$ and upregulated at $72 \mathrm{~h} ; 217$ genes were upregulated at $24 \mathrm{~h}$ and downregulated at $72 \mathrm{~h}$ (Fig. 1b).

Of all the unigenes, approximately $14.90 \%$ were annotated to seven databases, including NT, NR, UniProt database, RNAMMER, eggNOG, KEGG and GO. Using the GO classification (Fig. 1c-d), these DEGs participated in at least 58 biological activities and were characterized into three groups: cellular component, biological process and molecular function. For the cellular component, the high percentage of genes were concentrated in the cell part category ( $24 \mathrm{~h}$, up: 1242 genes, $17.46 \%$; down: 3423 genes, $16.03 \%$. $72 \mathrm{~h}$, up: 1078 genes, $27.05 \%$; down: 7244 genes, $18.51 \%$ ). The biological process group showed a significant percentage of genes assigned to metabolic process category $(24 \mathrm{~h}$, up: 1148 genes, 16.14\%; down: 2559 genes, $11.98 \%$. 72 h, up: 1022 genes, 25.65\%; down: 5490 genes, 14.03\%). For molecular function, the most represented ontology was catalytic activity (24h, up: 1240 genes, $17.44 \%$; down: 2077 genes, 9.73\%. 72 h, up: 996 genes, 24.99\%; down: 4187 genes, 10.7\%).

\section{Immune defensive pathways}

Considering that the immune response between $H$. parallela and $H$. beicherriana LF interaction is the key factor in the successful control of nematode parasitism, the transcripts related to immune defence responses upon nematode infection were selected. Through a complete search of the immune-related terms from the differential gene expression data, we identified a total of 74 DEGs that might be related to the immune defence mechanism in $H$. parallela. In this instance, differentially expressed transcripts were distributed among different immune response pathways, including recognition, activation of signalling pathways and production of effector molecules (Table 2). The results showed that most of the genes showed no significant expression change after treatment with nematodes for $24 \mathrm{~h}$, and many genes showed depressed expression after treatment with nematodes for $72 \mathrm{~h}$ relative to the control. However, some transcripts were induced for both treatment points, such as PGRPSC1, PPAE-I and GST, indicating that those genes may be involved in the immune responses to effectively resist nematode infection. The annotations of these genes in transcriptome data are summarized in Supplementary Table S1. These sequence data have been submitted to the GenBank databases under accession number DN15104, DN15190 and DN16733, respectively.

\section{Bioinformatics analysis of PGRP-SC1, PPAE-I and GST}

Based on the sequence analysis, PGRP-SC1 lacked a signal peptide but contained a transmembrane segment, which indicated that it may function on the cell membrane to recognize and bind pathogens. Moreover, PGRP-SC1 contains a highly conserved homologous PGRP domain consisting of approximately 130 amino acid residues at the shed terminal (Fig. 2a). It has also been noticed that two of five key residues responsible for zinc binding and amidase catalytic activity $\left(\mathrm{His}^{18}{ }^{18} \mathrm{Tyr}^{47}, \mathrm{His}^{123}\right.$, $\mathrm{Lys}^{129}$ (Thr in D. melanogaster PGRP-LB/SC1/SC2) and $\mathrm{Cys}^{131}$ in T7 lysozyme [40] were substituted from $\mathrm{His}^{18}$ to $\mathrm{Val}^{191}$ and from $\mathrm{Cys}^{131}$ to $\mathrm{Ser}^{303}$ in $H$. parallela PGRP-SC1 (Fig. 2b). The results of Pro-CHECK showed that 3D model of PGRP-SC1, PPAE-I and GST were all reasonably constructed (Supplementary Fig. S1). Among them, the 3D structure of PGRP-SC1 indicated that three peripheral $\alpha$ helices and five $\beta$-strands constitute the active domain center (Fig. 2c), and binding pocket was found in the protein surface (Fig. 2d). The phylogenetic analysis showed that $H$. parallela PGRP-SC1 (Hp SC1) clustered with O. taurus PGRP 2 (Ot 2) (Fig. 2e). 


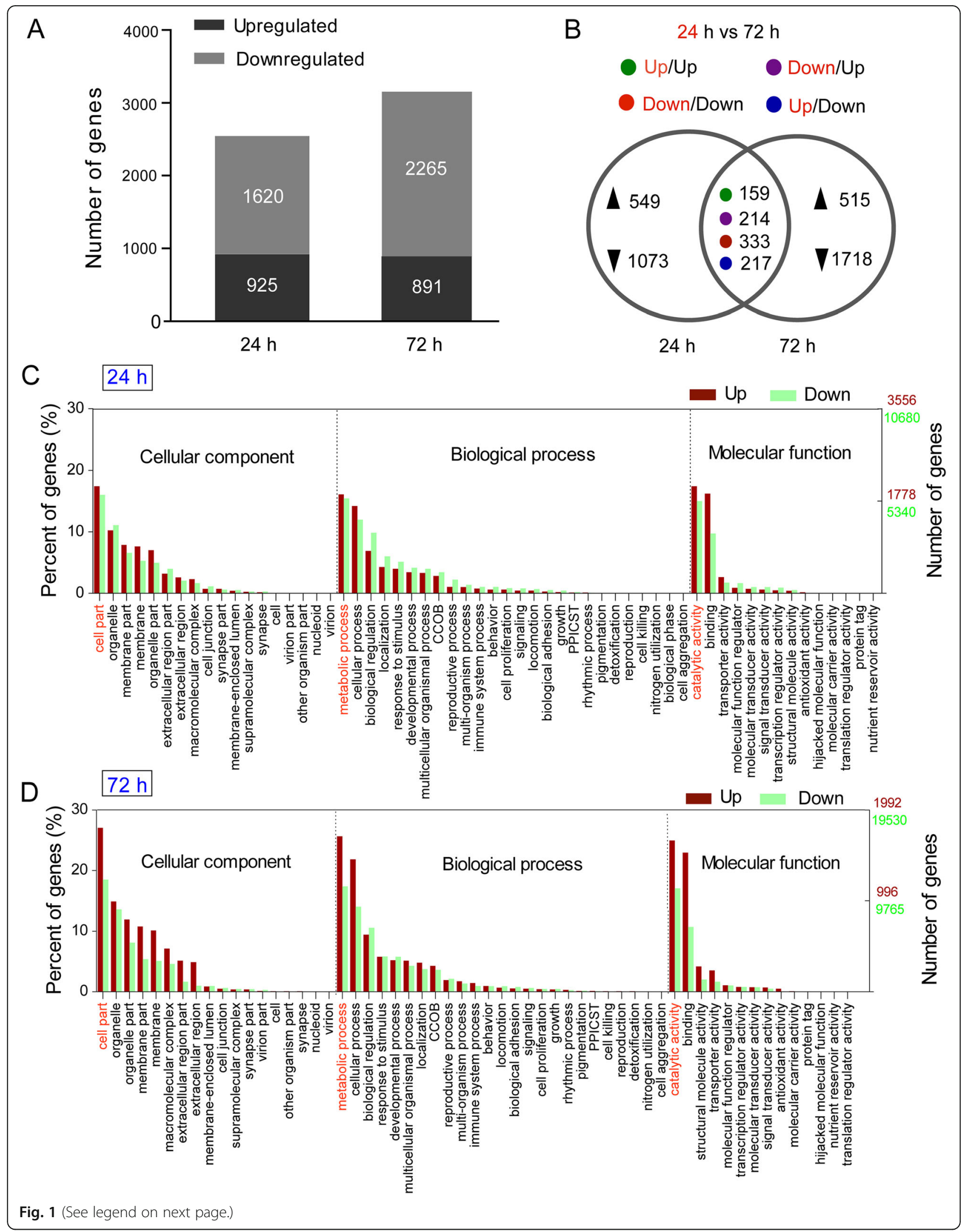


(See figure on previous page.)

Fig. 1 Transcriptome overview of Holotrichia parallela larvae after treatment with Heterorhabditis beicherriana LF. a The number of genes differentially expressed in $\mathrm{H}$. parallela after treatment with nematodes for 24 and $72 \mathrm{~h}$, respectively. $\mathbf{b}$ Venn diagrams showing the number of $H$. parallela genes that are differentially expressed (upregulated or downregulated) at $24 \mathrm{~h}$ only or at $72 \mathrm{~h}$ only or at both time-points after treatment with nematodes. Expression patterns are indicated (UP/UP: gene upregulation at both 24 and $72 \mathrm{~h}$, DOWN/UP: gene downregulation at $24 \mathrm{~h}$ and upregulation at $72 \mathrm{~h}$, DOWN/DOWN: gene downregulation at both time-points, UP/DOWN: gene upregulation at $24 \mathrm{~h}$ and downregulation at $72 \mathrm{~h}$ ). $\mathbf{c}$ and $\mathbf{d}$ Gene Ontology classification of the H. parallela larvae midgut transcript with Blast2GO program after treatment with $\mathrm{H}$. beicherriana LF for 24 and $72 \mathrm{~h}$. CCOB: cellular component organization or biogenesis; PPICST: presynaptic process involved in chemical synaptic transmission

Cleavage activation of pro-phenoloxidase mediated by clip domain SPs is critical to melanization, which could originate from melanin to promote wound healing, epidermal sclerosis, free radicals, and the aggregation and encapsulation of pathogens [41]. Sequence analysis showed that the open reading frame of $H$. parallela PPAE-I (a typical SP) contains 1095 nucleotides and 365 amino acids. We found that PPAE-I possessed a catalytic triangle composed of $\mathrm{His}^{155}$, $\mathrm{Asp}^{221}$ and $\mathrm{Ser}^{316}$. PROSITE analysis showed that PPAE-I was composed of a signal peptide (22 amino acid residues), a clip domain (51 amino acid residues) and a catalytic domain (255 amino acid residues). PPAE-I contains 12 extremely conserved cysteine residues and 6 in each of the two domains, which can form intramolecular disulphide bonds (Fig. 3a). In addition, the cutting site of PPAE-I was DEEK^ILGG, where it was recognized and activated by the upstream protease (Fig. $3 \mathrm{~b}$ ). The three highly conserved amino acids $\mathrm{Asp}^{310}, \mathrm{Ser}^{335}$ and G1y ${ }^{337}$ made up the active pocket of the PPAE-I substrate, which determines the specificity of PPAE-I substrate recognition (Fig. 3d). A calcium ion was anchored by $\mathrm{Glu}^{175}$ and Asp ${ }^{183}$, which may stabilize the overall structure of the PPAE-I domain (Fig. 3c). Further phylogenetic tree analysis showed that $H$. parallela PPAE-I (Hp PPAE-I) clustered close to Holotrichia diomphalia PPAF-I (Hd PPAF-I) with bootstrap values of 100 (Fig. 3e).

GSTs are the superfamily of multifunctional detoxification isoenzymes involved in the regulation of redox homeostasis and play crucial roles in innate immunity [42]. Sequence analysis showed that $H$. parallela GST genes possessed N/C-terminal domains, G/H-binding sites and dimer interfaces (polypeptide binding sites) (Fig. 4a-b). The GST structure exhibited the overall folding of sigma-class. Each monomer of $H$. parallela GST included nine $\alpha$-helices and four $\beta$-strands (Fig. 4c). One molecule of glutathione (GSH) bound to each $H$. parallela GST monomer and the binding site was located in the deep cleft between the two domains (Fig. 4d). Phylogenetic tree analysis indicated that most species were well differentiated with high bootstrap values, and $H$. parallela GST (Hp GST) clustered close to A. pisum GST (Api GST) (Fig. 4e).

\section{Spatiotemporal analysis of PGRP-SC1, PPAE-I and GST}

The expression patterns of PGRP-SC1, PPAE-I and GST genes were further determined in different developmental stages and tissues, respectively. The PGRP-SC1 was expressed throughout all developmental stages, exhibiting a low level at third instar larvae (Fig. 5a). PPAE-I exhibited a high level at first instar larvae (Fig. 5b). GST exhibited a high level at third instar larvae (Fig. 5c). For different tissues, PGRP-SC1 and PPAE-I had higher expressions in midgut and fat body, respectively, while GST exhibited high expression in both of them (Fig. 5d-f).

\section{qRT-PCR validation}

To validate the transcriptome results, qRT-PCR was performed. The qRT-PCR data shown the PGRP-SC1, PPAE-I and GST gene had a higher expression in the larvae of $H$. parallela treated with nematodes for $24 \mathrm{~h}$ with 4.66-, 3.37- and 4.40-fold, respectively, compared to the larvae treated with sterile water. After the larvae treated with nematodes for $72 \mathrm{~h}$, the fold changes were 2.92-, 1.06- and 3.00-fold, respectively (Fig. 6). The results obtained through qRT-PCR were in agreement with the transcriptome data on the fold changes of three candidate immune genes $\left(R^{2}=0.847, P=0.194\right.$ for $24 \mathrm{~h}$ and $R^{2}=0.909, P=0.256$ for $72 \mathrm{~h}$ at $95 \%$ confidence interval). The consistency of qRT-PCR results with transcriptome data confirmed the reliability and accuracy of sequencing results.

\section{The expression of PGRP-SC1, PPAE-I and GST after RNAi}

RNAi was used to study the functions and their effects on nematode infection resistance of PGRP-SC1, PPAE-I and GST. qRT-PCR confirmed that we successfully knocked down the genes following injection of dsRNAs into the second instar larvae of $H$. parallela (Fig. 7). The expression difference were not significant between control groups (dsGFP injected and water-injected) of those genes in different treatments. However, the expression of PGRP-SC1 and GST in the treatments (dsPGRP-SC1 and dsGST injected larvae) was both significantly reduced in comparison to the water injected larvae at $48 \mathrm{~h}$. The relative expression levels of these two genes were depressed by $92.18 \%$ (PGRP-SC1) and $77.00 \%$ (GST), respectively. The expression of PPAE-I in dsPPAE-I injected larvae was significantly depressed in comparison to the water injected larvae at 24,48 and $72 \mathrm{~h}$. The relative expression levels of PPAE-I were depressed by $95.83,99.10$ and $66.33 \%$, respectively. 
Table 2 List of transcripts associated with immune defence responses upon Heterorhabditis beicherriana LF infection

\begin{tabular}{|c|c|c|c|}
\hline \multirow[t]{2}{*}{ Unigene ID } & \multirow[t]{2}{*}{ Description } & \multicolumn{2}{|c|}{ Fold Change } \\
\hline & & $24 \mathrm{~h}$ & $72 \mathrm{~h}$ \\
\hline \multicolumn{4}{|l|}{ Recognition } \\
\hline TRINITY_DN9063_C0_g1 & Putative peptidoglycan binding domain & +2.06 & +2.13 \\
\hline TRINITY_DN14716_c5_g3 & Peptidoglycan recognition protein 2 & $=$ & -0.4 \\
\hline TRINITY_DN15104_C0_g1 & Peptidoglycan recognition protein $\mathrm{SC} 1 \mathrm{a} / \mathrm{b}$-like & +4.20 & +2.79 \\
\hline TRINITY_DN18918_C0_g2 & C-type lectin domain family & $=$ & +5.40 \\
\hline TRINITY_DN10984_C0_g1 & C-type lectin & -0.26 & $=$ \\
\hline TRINITY_DN16803_c1_g1 & C-type lectin domain family 16 , member A & $=$ & -0.19 \\
\hline TRINITY_DN14096_C0_g6 & Tubulointerstitial nephritis antigen-like & -0.44 & $=$ \\
\hline TRINITY_DN11464_c1_g3 & Flocculation protein FLO11-like & $=$ & -0.01 \\
\hline TRINITY_DN15762_c1_g2 & Flocculation protein FLO11 isoform X3 & $=$ & -0.11 \\
\hline TRINITY_DN10144_C0_g1 & Scavenger receptor class $B$, member & +2.44 & $=$ \\
\hline TRINITY_DN20348_c0_g1 & Scavenger receptor cysteine-rich domain & +2.14 & $=$ \\
\hline TRINITY_DN10223_C0_g1 & Scavenger receptor class B member 1 & -0.28 & +3.80 \\
\hline TRINITY_DN20348_C0_g1 & Scavenger receptor activity & +2.14 & $=$ \\
\hline TRINITY_DN10537_CO_g1 & Somatomedin_B & -0.50 & -0.00 \\
\hline \multicolumn{4}{|c|}{ Activation of signalling pathway } \\
\hline TRINITY_DN16123_c1_g1 & Tyrosine-protein phosphatase Lar isoform X2 & $=$ & -0.04 \\
\hline TRINITY_DN12585_C0_g9 & Receptor-type tyrosine-protein phosphatase kappa & - & +6.63 \\
\hline TRINITY_DN14569_C0_g1 & Tyrosine-protein phosphatase 69D & -0.32 & -0.02 \\
\hline TRINITY_DN11667_C0_g2 & Tyrosine-protein phosphatase non-receptor type 14 & $=$ & -0.13 \\
\hline TRINITY_DN20113_c2_g1 & Tyrosine-protein phosphatase non-receptor type 23 & $=$ & -0.36 \\
\hline TRINITY_DN14547_c0_g2 & Tyrosine-protein phosphatase non-receptor type 4 & -0.39 & -0.05 \\
\hline TRINITY_DN16319_c2_g1 & Receptor-type tyrosine-protein phosphatase N2 & $=$ & -0.07 \\
\hline TRINITY_DN17938_CO_g1 & Tyrosine-protein phosphatase non-receptor type 7 & +2.05 & -0.28 \\
\hline TRINITY_DN13499_C0_g2 & Receptor-type tyrosine-protein phosphatase $T$ & -0.18 & -0.14 \\
\hline TRINITY_DN20215_c1_g2 & Tyrosine-protein phosphatase 10D & $=$ & -0.49 \\
\hline TRINITY_DN20215_c1_g4 & Receptor-type tyrosine-protein phosphatase beta & $=$ & -0.15 \\
\hline TRINITY_DN15387_C0_g1 & Zinc finger protein 1 & -0.04 & -0.00 \\
\hline TRINITY_DN18572_c2_g2 & Zinc finger protein 711 -like & -0.27 & -0.41 \\
\hline TRINITY_DN12683_C0_g1 & Zinc finger protein 182 & $=$ & -0.46 \\
\hline TRINITY_DN15982_c3_g10 & Zinc finger protein Gfi-1 & $=$ & -0.09 \\
\hline TRINITY_DN12684_C0_g1 & Zinc finger protein 26 & $=$ & -0.09 \\
\hline TRINITY_DN18098_c2_g2 & Zinc finger protein 710 & $=$ & -0.11 \\
\hline TRINITY_DN14971_c1_g1 & Zinc finger protein 782 & -0.31 & -0.03 \\
\hline TRINITY_DN15174_C0_g2 & Zinc finger protein 431 -like isoform $\times 2$ & -0.39 & -0.00 \\
\hline TRINITY_DN14699_c1_g3 & JNK_SAPK-associated protein-1 & $=$ & -0.25 \\
\hline TRINITY_DN7086_C0_g1 & Transcription factor Sox-9-B-like & -0.24 & -0.32 \\
\hline TRINITY_DN18891_C1_g2 & Interferon-related developmental regulator 2 & +2.06 & +4.00 \\
\hline TRINITY_DN18878_C0_g2 & Protein lingerer & $=$ & -0.19 \\
\hline TRINITY_DN18219_C2_g1 & Serine protease inhibitor 42Dd & $=$ & -0.26 \\
\hline TRINITY_DN15260_c0_g2 & Serine protease snake & +5.77 & +4.49 \\
\hline TRINITY_DN18055_c3_g1 & Serine protease inhibitor $88 \mathrm{Ea}$ & -0.06 & -0.01 \\
\hline TRINITY_DN15190_C0_g1 & Pro-phenoloxidase activating enzyme-I precursor & +3.47 & $=(1.21)$ \\
\hline
\end{tabular}


Table 2 List of transcripts associated with immune defence responses upon Heterorhabditis beicherriana LF infection (Continued)

\begin{tabular}{|c|c|c|c|}
\hline \multirow[t]{2}{*}{ Unigene ID } & \multirow[t]{2}{*}{ Description } & \multicolumn{2}{|c|}{ Fold Change } \\
\hline & & $24 \mathrm{~h}$ & $72 \mathrm{~h}$ \\
\hline \multicolumn{4}{|c|}{ Production of effector molecules } \\
\hline TRINITY_DN13192_C1_g2 & Chorion peroxidase-like & -0.23 & -0.03 \\
\hline TRINITY_DN10094_C0_g1 & Attacin_C & -0.15 & $=$ \\
\hline TRINITY_DN13744_c1_g3 & ATP $^{\dagger}$-dependent RNA helicase p62 & $=$ & -0.49 \\
\hline TRINITY_DN11082_c2_g2 & ATP-dependent RNA helicase & $=$ & -0.04 \\
\hline TRINITY_DN17995_c3_g1 & ATP-dependent RNA helicase WM6 & $=$ & -0.14 \\
\hline TRINITY_DN16001_C1_g1 & ATP-dependent RNA helicase DHX8 & -0.48 & -0.26 \\
\hline TRINITY_DN20149_CO_g1 & ATP-dependent RNA helicase DDX5/DBP2 & $=$ & -0.17 \\
\hline TRINITY_DN14053_C1_g1 & ATP-dependent RNA helicase Ddx1 & $=$ & -0.26 \\
\hline TRINITY_DN16098_C1_g1 & ATP-dependent RNA helicase A & -0.38 & -0.16 \\
\hline TRINITY_DN15118_C0_g3 & ATP-dependent RNA helicase DDX24 & $=$ & -0.12 \\
\hline TRINITY_DN19567_c0_g2 & ATP-dependent RNA helicase TDRD12 & -0.26 & -0.06 \\
\hline TRINITY_DN14329_C0_g2 & Spermatogenesis-associated protein 20 & $=$ & -0.28 \\
\hline TRINITY_DN18323_c2_g1 & Spermatogenesis-associated protein 13 & -0.29 & -0.09 \\
\hline TRINITY_DN17965_C1_g1 & Spermatogenesis-associated protein 5 & $=$ & -0.28 \\
\hline TRINITY_DN18625_c3_g1 & Spermatogenesis-associated protein 13-like isoform X1 & $=$ & -0.25 \\
\hline TRINITY_DN14329_CO_g2 & Spermatogenesis-associated protein 2 & $=$ & -0.28 \\
\hline TRINITY_DN11114_C0_g1 & Probable chitinase 10 & $=$ & -0.08 \\
\hline TRINITY_DN9400_c0_g1 & Probable chitinase 2 & $=$ & -0.20 \\
\hline TRINITY_DN11052_c6_g2 & Protein takeout-like & -0.14 & -0.49 \\
\hline TRINITY_DN17266_c1_g3 & Gamma-glutamyltransferase activity & -0.13 & -0.21 \\
\hline TRINITY_DN14465_C2_g4 & Hemocyte protein-glutamine gamma-glutamyltransferase & -0.16 & -0.26 \\
\hline TRINITY_DN16733_C0_g1 & Glutathione-S-transferase & +4.46 & +3.61 \\
\hline TRINITY_DN10980_C0_g1 & Phenoloxidase subunit 1 & -0.23 & -0.25 \\
\hline TRINITY_DN15456_c3_g3 & Nitric oxide-associated protein 1 & $=$ & -0.22 \\
\hline TRINITY_DN16202_C0_g1 & Nitric oxide synthase interacting protein & $=$ & -0.63 \\
\hline TRINITY_DN15462_C1_g1 & Heat shock protein & +4.89 & -0.39 \\
\hline TRINITY_DN9876_c0_g1 & Heat shock protein 26 & $=$ & +4.53 \\
\hline TRINITY_DN6424_CO_g1 & Heat shock protein 90 & -0.34 & $=$ \\
\hline TRINITY_DN8346_CO_g1 & Heat shock protein TC005094 & -0.24 & $=$ \\
\hline TRINITY_DN16097_c1_g1 & Heat shock protein $75 \mathrm{kDa}$ & $=$ & -0.33 \\
\hline TRINITY_DN19512_C2_g3 & Heat shock protein $67 \mathrm{~B} 2$ & +14.52 & $=$ \\
\hline TRINITY_DN11437_c3_g4 & Farnesyl pyrophosphate synthase & $=$ & -0.09 \\
\hline TRINITY_DN13560_C2_g5 & Protein farnesyltransferase & $=$ & -0.08 \\
\hline
\end{tabular}

Note: Symbols +, - and = indicate significant upregulation, downregulation and no significant expression change, respectively. t: Adenosine triphosphate

Susceptibility to Heterorhabditis beicherriana LF after RNAi The susceptibility of $H$. parallela second instar larvae was investigated after we silenced PGRP-SC1, PPAE-I and GST (Fig. 8). After injection of dsPGRP-SC1, dsPPAE-I or dsGST for $48 \mathrm{~h}$, the larvae were exposed to nematodes (100 and $200 \mathrm{IJ}$ /grub)-incorporated diets for $24 \mathrm{~h}$, and the larvae exhibited a higher mortality than the control larvae injected with dsGFP and water. While
dsGFP did not show significant differences to water control, the mortality of $H$. parallela larvae injected with dsPGRP-SC1 or dsPPAE-I was significantly higher than water injected control by increased $41.66 \%$ or $33.33 \%$ when exposed to nematodes at $100 \mathrm{IJs} /$ grub and $24.08 \%$ or $25.00 \%$ at $200 \mathrm{IJs} /$ grub. The mortality of $H$. parallela larvae was significantly different between the injection of dsGST and water injected control by increased $16.67 \%$ 


\section{A \\ PGRP-SC1

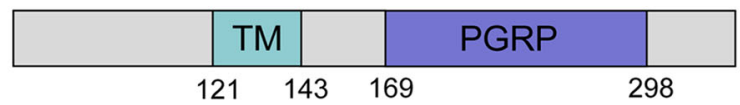 \\ B MSSTEVILNLPPILQNAANTYKTETLEYNAEILSQCSTEDKDVCSNSVSD \\ FPMISIVNSSDVI IGSVTQFHGPVTIVQQQASPKEGIEDKKNEADMVATD Transmembrane domain \\ YKTKAAPKKPAAPQHCLPKRILICFAVLTLLITLIALSVILMLEKRYDTD GDVLSTYNETNQYEYTVTEWGGKQPLSKEAITNPVRYVI IVHTAGVFCNT FLECAAQVQLAQDLHVTKDEPNIKYNFVIGGDGN IYEGRGWSVKNSLRDD SISVAFIGNFIYDELLPSMLDALLELIESGRHLGVLPDSYRIVAHNQTAP} TLS PGRNVYKVIKELAHFYPDLTPVIRN

C

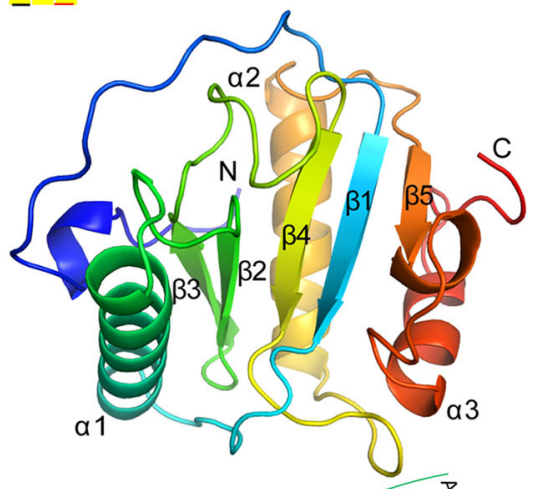

E

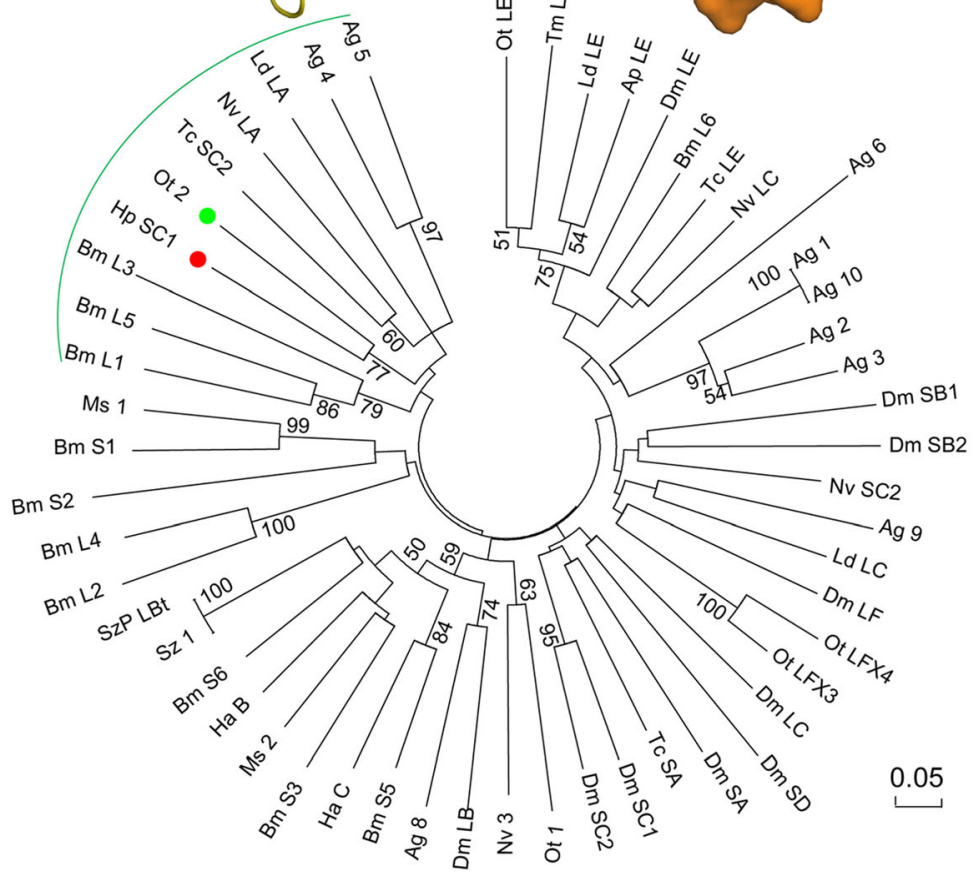

Fig. 2 Bioinformatics analysis of Holotrichia parallela PGRP-SC1. a Schematic representation of H. parallela PGRP-SC1. The transmembrane domain (TM) and PGRP homologous domain (PGRP) are indicated in wathet blue and purple boxes, respectively. b Sequence analysis of $H$. parallela PGRP-SC1. The domain division (TM and PGRP) are indicated above the sequences. The amidase catalytic site is underlined. The Zn binding residues are shown in red. The substrate binding site are shown in yellow shading. $\mathbf{c}$ The overall structure of H. parallela PGRP-SC1. The N-terminus (N), C-terminus (C), $a$-helices and $\beta$-strands are labeled. $\mathbf{d}$ Surface of H. parallela PGRP-SC1 structure. Substrate binding sites are colored green. e Phylogenetic analysis of H. parallela PGRP-SC1. The red and green circles highlight H. parallela PGRP-SC1 and the closely homologous specie PGRP, respectively. Numbers at the nodes were bootstrap values as percentage and only bootstrap values greater than 50 are shown. The same for Figs. 3-e and 4-e. Scale bar, 0.05 substitutions per site 


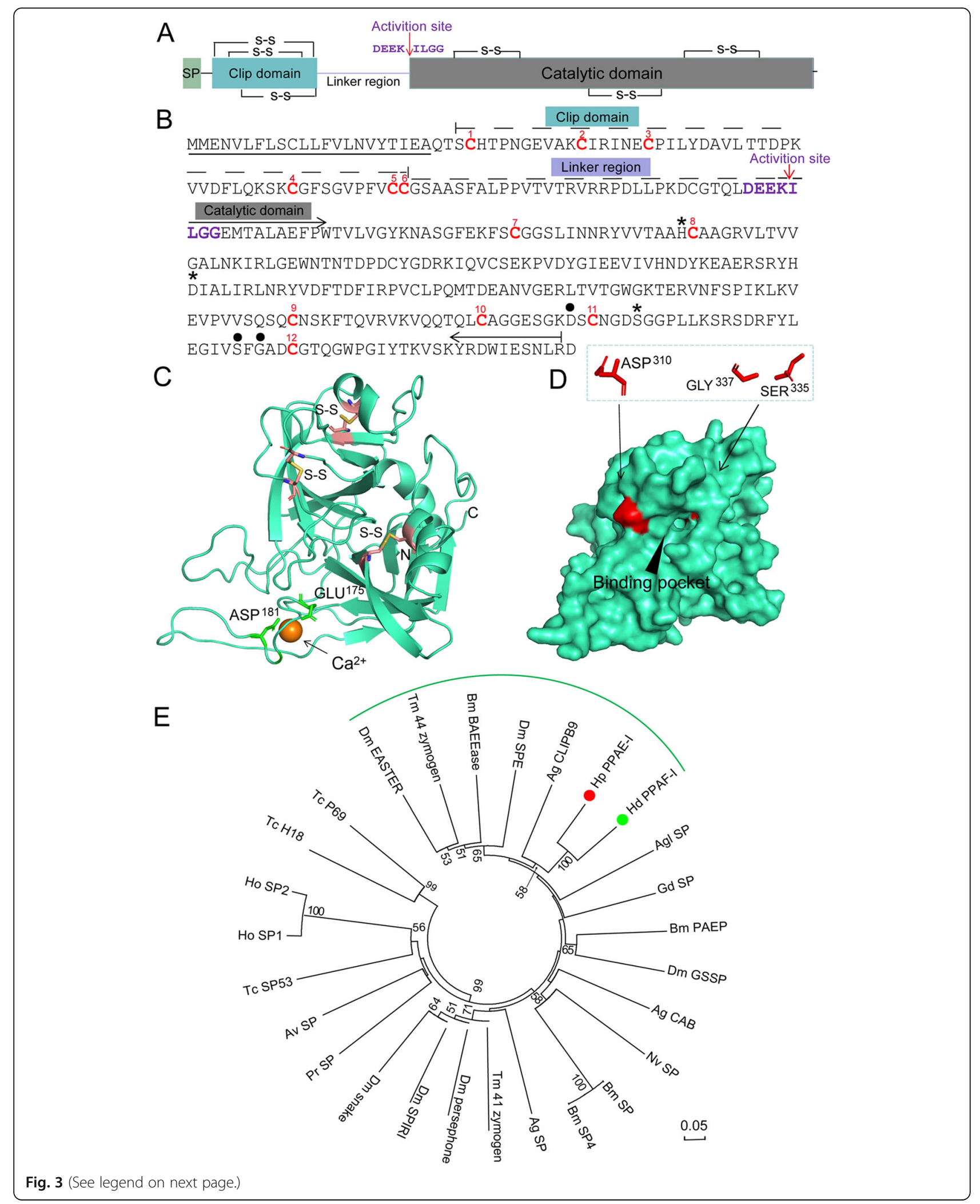


(See figure on previous page.)

Fig. 3 Bioinformatics analysis of Holotrichia parallela PPAE-I. a Schematic representation of H. parallela PPAE-I. Signal peptide (SP) are indicated in green boxes. The disulfide linkages are shown in lines with a symbol (S-S). The position of the peptide bond cleaved during activation is indicated by red arrow. $\mathbf{b}$ Sequence analysis of H. parallela PPAE-I. The predicted secretion signal peptide is underlined. The domain divisions (one clip domain and one catalytic domain) are indicated above the sequence. The absolutely conserved Cys residues in clip domain and catalytic domain are numbered and shown in red. Clip domain is predicted to form three disulfide bonds (1-5, 2-4, 3-6). Catalytic domain is also predicted to form three disulfide bonds $(7-8,9-10,11-12)$. The residues of the catalytic triad $\left(\mathrm{His}^{155}, \mathrm{Asp}^{221}\right.$, Ser $\left.{ }^{316}\right)$ are indicated by asterisks. The important determinants of the specificity pocket in the catalytic domain $\left(\mathrm{Asp}^{310}, \mathrm{Ser}^{335}, \mathrm{Gly}^{357}\right.$ ) are marked by black circles. The potential cleavage activation sites are shown in purple and labeled by red arrow. c The overall structure of H. parallela PPAE-I. The N-terminus (N), C-terminus (C), calcium ion and disulfide bridges are labeled. $\mathbf{d}$ Surface of H. parallela PPAE-I structure. Substrate binding sites are colored red. e Phylogenetic analysis of H. parallela PPAE-I. The red and green circles highlight H. parallela PPAE-I and the closely homologous specie SP, respectively. Scale bar, 0.05 substitutions per site

when exposed to nematodes at $100 \mathrm{IJs} /$ grub, whereas the larvae only exhibited a slightly higher mortality by increased $12.97 \%$ at $200 \mathrm{IJs} /$ grub.

\section{Discussion}

As one of the most important destructive belowground herbivores in China, the larvae of $H$. parallela have caused considerable damage to crop production [1]. To date, many studies have proven that EPNs are compatible alternatives to conventional insecticides for the larvae of $H$. parallela because they not only can actively search for their hosts in soil but also possess the property of fast-acting than other biological agents [12, 43]. Meanwhile, combating to the host immune response are regarded as crucial to successful parasitism [28]. Thus, the immune and anti-immune mechanisms between $H$. parallela and EPNs are urgently to clarify. In this study, we carried out RNA-Seq to screen the DEGs involved in the immune response of $H$. parallela against EPNs infection and functionally validated three crucial immunerelated genes using in vivo RNAi technology.

Through comparative analysis, 925 transcripts were induced upon nematode challenge for $24 \mathrm{~h}$ in our grubs, whereas only 314 genes were induced in $H$. virescens larvae after exposure to $H$. bacteriophora for $23 \mathrm{~h}$ [39]. However, homologue of thioester-containing complement protein 3 , basement membrane component (glutactin) and recognition protein (GNBP-like 3) which were not identified in the 74 DEGs implicating in immune responses of $H$. parallela has been proven to be involved in the immune responses of Drosophila larvae against $H$. bacteriophora (H222 strain) infection [38]. Therefore, we think the immune responses between white grubs and Drosophila against nematodes infection were different. In addition, some sequences respond to symbiotic bacterium were detected after treatment with nematodes for $72 \mathrm{~h}$ (Supplementary Table S2). Previous studies have shown that $10 \%$ of $H$. bacteriophora can escape the encapsulation of $P$. japonica larvae after entering for $24 \mathrm{~h}$ [44] and the escaped nematodes will release symbiotic bacteria $30 \mathrm{~min}$ later [45]. Thus, the symbiotic bacteria of $H$. beicherriana LF was predicted to participate in immune responses after $H$. parallela larvae treated with the nematode for $72 \mathrm{~h}$.

Identification of parasite/pathogen invasion in the host is the initial step in the initiation of immune responses, and this process relies on biosensor proteins called pattern recognition receptors (PRRs), which can detect and bind to certain pathogen-associated molecular patterns (PAMPs) on the surface of invading microbes or foreign bodies [46, 47]. PGRPs are important members of insect PRRs and play an important role in innate immunity $[48,49]$. Previous studies have shown that PGRP-LB1, -LB2, -LC2, -LC3 and -LD in Monochamus alternatus are likely to encode membrane proteins [50]; PGRP-SC1 of $H$. parallela contains a similar structure (without a signal peptide but containing a transmembrane segment), indicating that it may function on the cell membrane to recognize and trigger immune responses. Moreover, 2 of 5 key residues responsible for zinc binding and amidase catalytic activity were substituted, indicating that $H$. parallela PGRP-SC1 has no amidase activity and cannot cleave the bacterial peptidoglycan (PGN) [51]. However, this type of PGRP may function as a sensor for ligand-dependent signalling to activate the pro-phenoloxidase (PPO) cascade [52]. For example, overexpression of PGRP-LE in D. melanogaster led to the activation of the PPO cascade [53]. Therefore, we speculate that $H$. parallela PGRP-SC1 may participate in the PPO cascade reaction as a signal recognition receptor. Further phylogenetic analysis of PGRP showed that $H$. parallela PGRP-SC1 and B. mori PGRP-L1 were in a cluster. It is already known that PGRP-L1 in $B$. mori could induce the expression of antigen processing machinery (APM) genes and may be players in the immune deficiency (IMD) pathway [54]. Therefore, we speculate that $H$. parallela PGRP-SC1 may also be involved in the IMD pathway. However, the detailed functionality of PGRP-SC1 in $H$. parallela merits further studies with more biochemical methods.

Once the insect PRRs recognize the pathogen, the second step of innate immune-signal modulation is immediately initiated. At this time, the cascade reaction of SPs mainly relies on continuously expanding signals and eventually transmitting the signals to the nucleus [55]. 
A

\section{A}

GST N-terminal

GST C-term-site

B

GST N-terminal

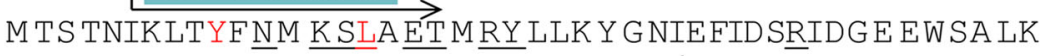

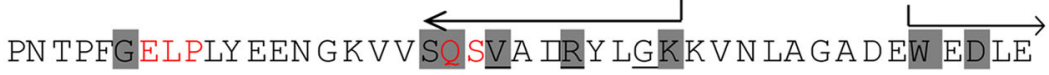

IDALVDTIKDLQIKLIPYA HAKM A DNKEKQ EELKQIILSETMPYY

LKKEESIVIENNG HFIKD KLT $\underline{W}$ ADI Y YFT T NVDIYNAV LD M DVLEK

GST C-terminal

Y PD LLK LKN KVEEIPSIKAWIEVRPETEF

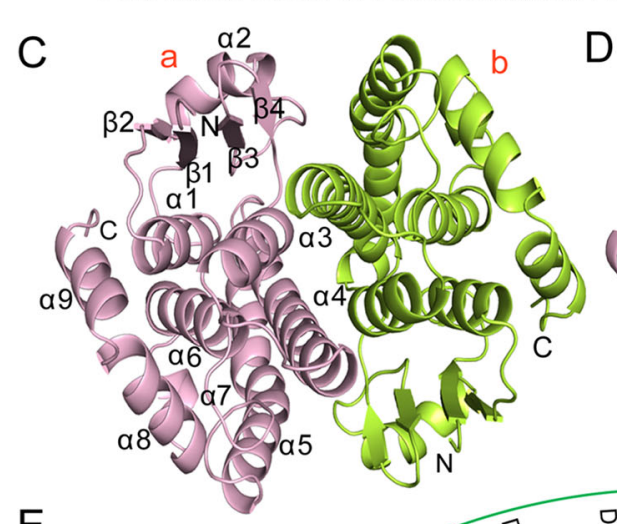

$\mathrm{E}$

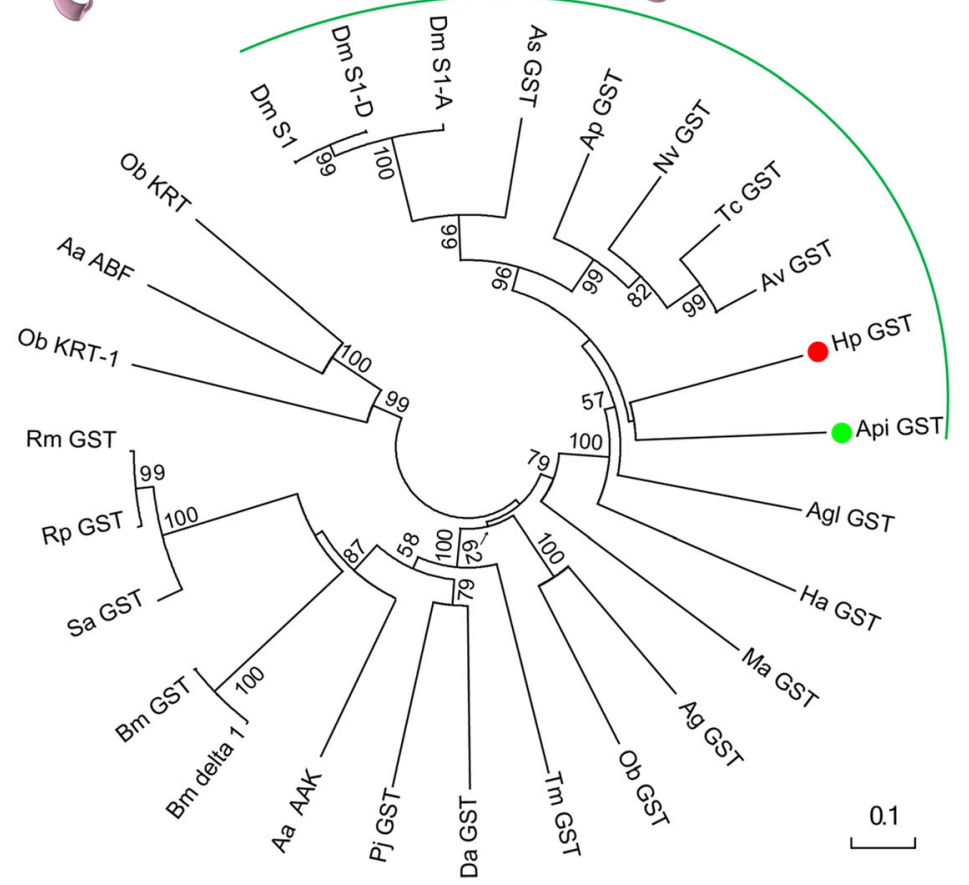

Fig. 4 Bioinformatics analysis of Holotrichia parallela GST. a Schematic representation of H. parallela GST. The GST N-terminal and GST C-terminal are indicated in wathet blue and purple boxes, respectively. The $\mathrm{G}$-site and $\mathrm{H}$-site are shown above the boxes. $\mathbf{b}$ Sequence analysis of $\mathrm{H}$. parallela GST. The GST N-terminal and GST C-terminal are indicated above the sequences. The GSH binding sites (G-site) are shown in red. The dimer interface (polypeptide binding site) is shown in dark grey. The C-terminal domain interface is underlined. The substrate binding pocket ( $\mathrm{H}$-site) is shown in purple. The N-terminal domain interface (polypeptide binding site) is underlined and tiltedc The overall structure of H. parallela GST. The N-terminus (N), C-terminus (C), $a$-helices and $\beta$-strands are labeled. ' $a$ ' and ' $b$ ' means the GST monomer, respectively. $\mathbf{d}$ The overall structure of H. parallela GST monomer. GSH binding sites are colored green. e Phylogenetic analysis of H. parallela GST. The red and green circles highlight H. parallela GST and the closely homologous specie GST, respectively. Scale bar, 0.1 substitutions per site. 

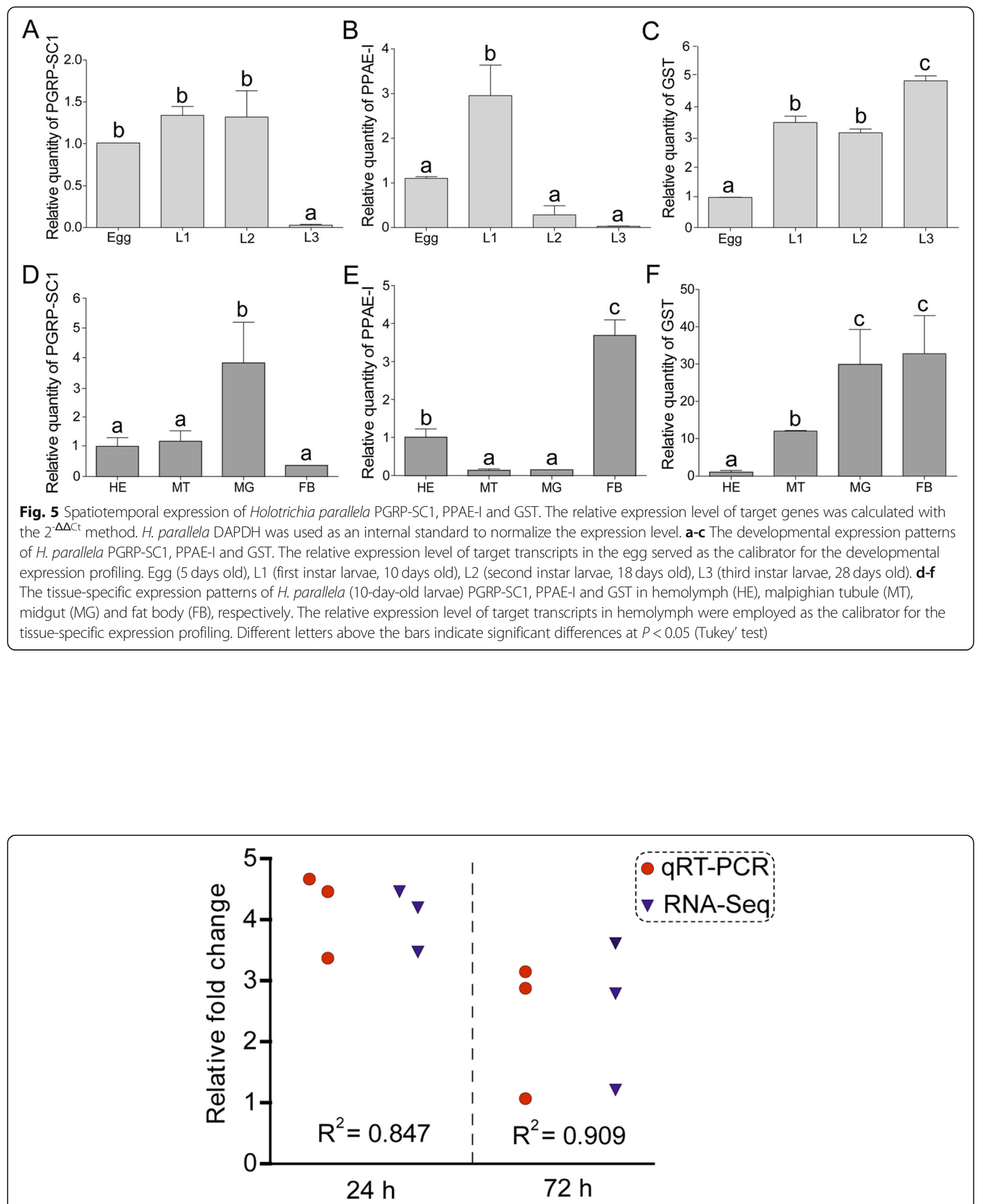

Fig. 6 qRT-PCR validation of the transcriptome data in Holotrichia parallela larvae postexposure to Heterorhabditis beicherriana LF. The relative fold changes in qRT-PCR are presented as the means of three biological replicates. The relative expression level of target genes was calculated with the $2^{-\Delta \Delta C t}$ method based on the value of water (control) that was ascribed an arbitrary value of 1. H. parallela DAPDH was used as an internal standard to normalize the expression level. $R^{2}$ means the square of correlation coefficient 
A

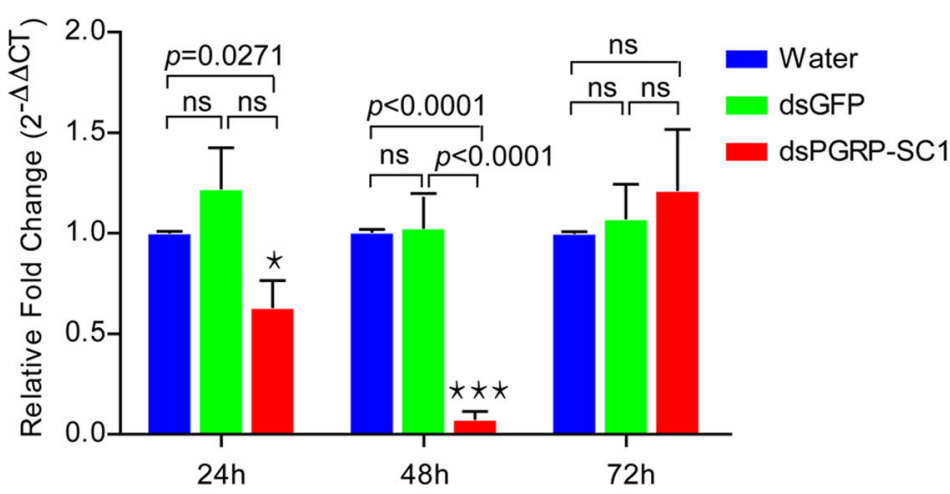

B
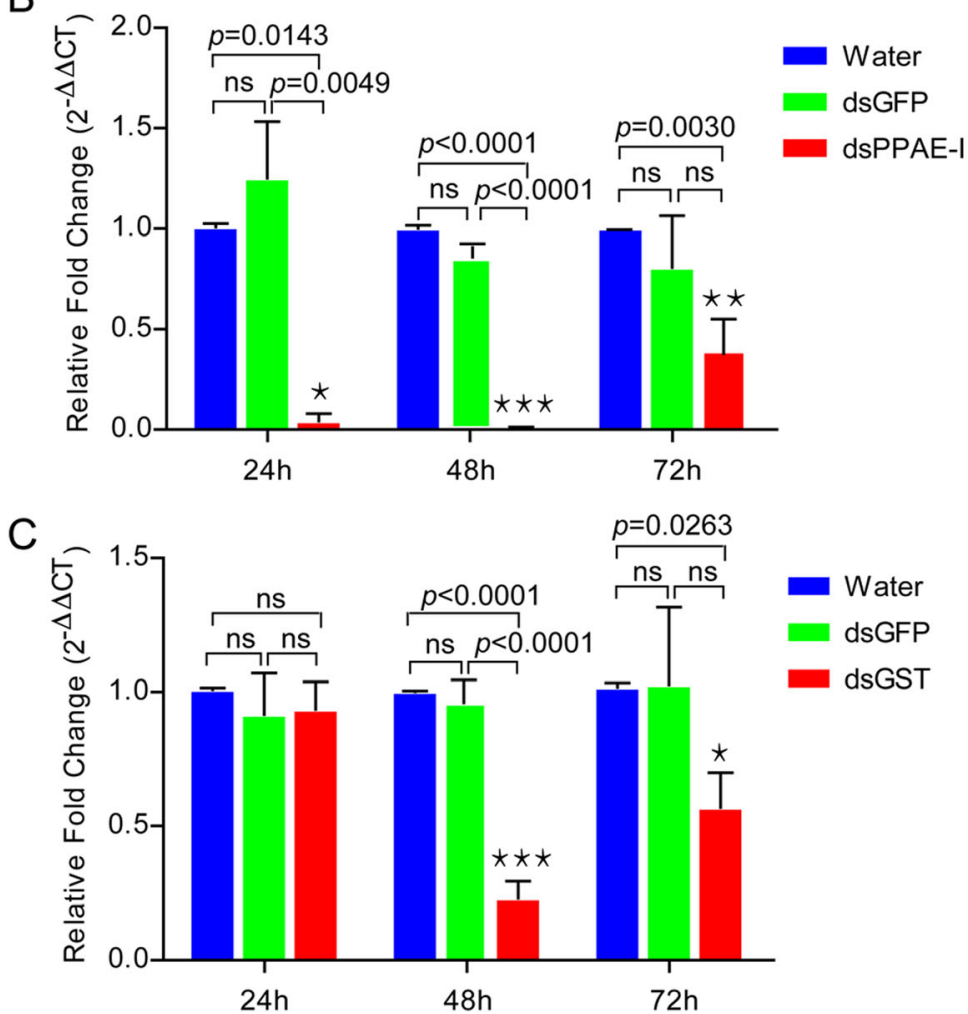

Fig. 7 Relative expression level of PGRP-SC1, PPAE-I and GST after RNAi. Data are means \pm SEM of three biological replicates, and the relative expression was calculated using the $2^{-\Delta \Delta \mathrm{Ct}}$ method based on the value of water (control) at 24,48 , and $72 \mathrm{~h}$ that was ascribed an arbitrary value of 1 . Statistical differences were determined by multiple $t$-test at the significance levels set at ${ }^{*} P<0.05,{ }^{* *} P<0.01,{ }^{* *} P<0.001$, NS, not significant

Our research indicated that $H$. parallela PPAE-I was a typical serine protease with a clip domain and a catalytic domain, and further phylogenetic tree analysis showed that $H$. parallela PPAE-I clustered close to $H$. diomphalia PPAF-I. Previous findings have demonstrated that clip domain SPs are actively involved in the prophenoloxidase-activation cascade [56, 57]. Moreover, $H$. diomphalia PPAF-I could activate $H$. diomphalia PPO in the presence of PPAF-II [58]. In summary, $H$. parallela PPAE-I may function in inducing pro- phenoloxidase activity and mediating the melanization response.

GST is a widespread multigene family of detoxification enzymes and acts as an effector molecule after induction by immunization in innate immunity [59]. GST has a variety of functions, including detoxification of endogenous and/or xenobiotic compounds and protection of cells from oxidative damage, whereas other functions may include contributing to metabolic and signalling pathways $[60,61]$. A number of studies have shown that 

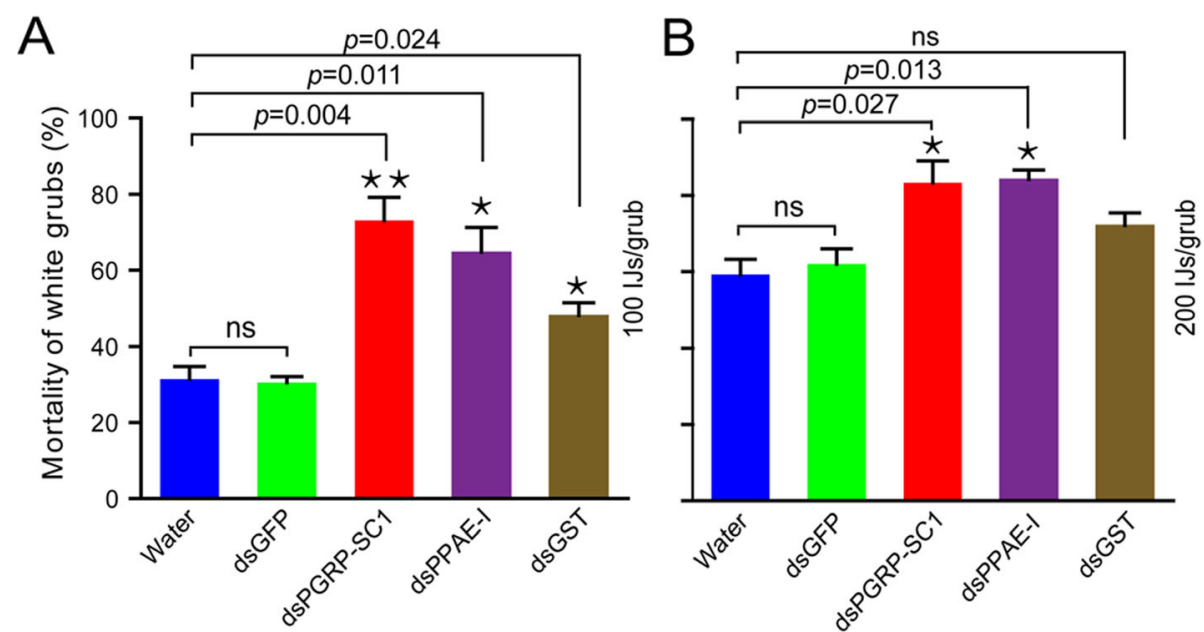

Fig. 8 The mortality of white grubs exposed to H. beicherriana LF for $24 \mathrm{~h}$ (A: $100 \mathrm{lJ} / \mathrm{grub} ; \mathrm{B}: 200 \mathrm{IJs} / \mathrm{grub}$ ) after dsRNA injection. Data are means \pm SEM. Statistical differences were determined by multiple $t$-test at the significance levels set at ${ }^{*} P<0.05,{ }^{* *} P<0.01,{ }^{* *} P<0.001$, NS, not significant

GST is generally induced by immunization and acts as an effector to regulate the metabolism of exogenous toxic substances. For instance, T. castaneum GST was activated to defend against lipopolysaccharide (LPS)challenge [62], and P. brevitarsis GST was upregulated in response to $E$. coli challenge [24]. In addition, sequence analysis showed that $H$. parallela GST possessed the characteristics of the GST family, and phylogenetic analysis indicated that $H$. parallela GST and D. melanogaster/N. vespilloides GST were in a cluster, which has been proven to respond to microbial challenge [63, 64]. In general terms, $H$. parallela GST may play a partial immune protection role in $H$. parallela against nematode infection.

Then, the roles of these three genes were determined by dsRNA injection-mediated RNAi and pathogenicity assays. The results showed that silencing of PGRP-SC1 and PPAE-I resulted in significant susceptibility of $H$. parallela to nematodes, and the mortality of $H$. parallela larvae was increased to different degrees compared to that of the control (water-injected). In addition, silencing of GST also resulted in increased susceptibility of $H$. parallela to nematodes. These results suggest that PGRP-SC1, PPAE-I, and GST are involved in immune responses to resist nematode infection.

\section{Conclusions}

Overall, our study strongly support that PGRP-SC1, PPAE-I and GST are genes related to nematode resistance in $H$. parallela, and the detailed functionalities of these genes deserve further investigation. Meanwhile, these results may help to elucidate the nematode resistance mechanism and provide valuable insights in designing appropriate resistance management strategies for this famous agricultural pest. In addition, more studies are needed to elucidate the immune mechanisms between $H$. parallela and symbiotic bacteria of $H$. beicherriana LF or other kinds of EPNs.

\section{Methods}

Nematode and insect culture

Entomopathogenic nematode $H$. beicherriana LF were cultured in vivo on larvae of the greater wax moth (Galleria mellonella) at $25^{\circ} \mathrm{C}$ and $80 \%$ relative humidity $(\mathrm{RH})$. Released infective juveniles were collected and stored at $7 \pm 1^{\circ} \mathrm{C}$ for no more than 15 days before use [65]. The larvae of $H$. parallela were fed germinated wheat seeds, and actively feeding grubs (approximately 13 days old and at the beginning of second instar) were kept individually in the holes of six-well bioassay trays (Corning Inc., NY, USA) filled with $15 \mathrm{~g}$ and 18\% soil moisture $(\mathrm{w} / \mathrm{w})$ of high temperature sterilized sandy loam soil (76\% sand, $16 \%$ silt, $6 \%$ clay, $0.5 \%$ organic matter; $\mathrm{pH}$ 6.7) for use.

\section{Nematode infection to Holotrichia parallela}

One hundred IJs were added into each hole of the sixwell bioassay trays described above. A total of $60 \mathrm{H}$. parallela larvae were treated with nematodes, and control group was treated with sterile water. The six-well bioassay trays were then transferred into a dark incubator under the following conditions: $25^{\circ} \mathrm{C}$ and $80 \% \mathrm{RH}$. The midgut samples ( $n=3$ for each treatment) of $H$. parallela used for RNA-Seq were collected in RNase-free tubes at $24 \mathrm{~h}$ and $72 \mathrm{~h}$ after treatment with nematodes or sterile water following the method below.

\section{Disintegration of Holotrichia parallela midgut}

$H$. parallela larvae treated with nematodes or sterile water were transferred on ice for $1 \mathrm{~min}$ and then placed 
on a precooled petri dish $(d=15 \mathrm{~cm})$. After adjusting the focal length of SMZ-168 Stereo Zoom microscope (Sinolab Inc., Beijing, China) until the insect body could be observed clearly, the head and tail of the larvae were cut off with scissors and the whole midgut was carefully pulled out using tweezers. The malpighian tubule and fat around the midgut were removed with tweezers, and the peritrophic membrane was pulled to remove all food particles in the midgut. After three rinses with RNasefree water, three samples for each treatment were collected in a $1.5 \mathrm{ml}$ RNase-free tube and stored at $-80^{\circ} \mathrm{C}$ for RNA isolation. The experiment was performed with two replicates of each treatment for RNA-Seq.

\section{RNA isolation and CDNA library preparation}

Total RNA was extracted using TRIzol Reagent (Invitrogen, Carlsbad, CA, USA) following the manufacturer's protocol followed by ethanol/isopropanol precipitation and suspended in a final volume of $30 \mu \mathrm{l}$ with RNasefree water. After extraction, the total RNA quality of different treatments were measured with NanoDrop 2000 spectrophotometer (Thermo Scientific) and in a $1.5 \%$ agarose gel. RNA integrity and concentration were subsequently analyzed using 2100 RNA Nano 6000 Assay Kit (Agilent Technologies, CA, USA).

Following the Illumina protocols, $2 \mu \mathrm{g}$ RNA of different treatment was used for cDNA library construction, and each treatment was replicated two times. Following the use of oligo (dT) magnetic beads, fragmentation of mRNA, generation of the first strand cDNA with a random hexamer primer and synthesis of second strands, cDNA end repair and adenylation at the $3^{\prime}$ end, and adapter ligation and cDNA fragment enrichment were performed. Then, the cDNA products were purified and amplified by PCR to create the final cDNA library.

\section{RNA-Seq and de novo assembly}

Paired-end sequencing was conducted on an Illumina HiSeq 2000 (Illumina Inc., USA) at Anoroad Genomics Co., Ltd. (Beijing, China). After sequencing, the raw reads were filtered to generate clean reads. First, the reads with adapters were removed, and then the reads with $>5 \%$ unknown bases $(\mathrm{N})$ were discarded. Finally, the low-quality reads (with $>50 \%$ of nucleotides for which the Phred Quality Score Q was less than or equal to 19) were filtered out.

The clean reads of each treatment were loaded to Trinity (Trinity Release v2.4.0) [66] for de novo assembly under the paired-end mode with default parameters. Based on the filtered clean data, the full-length transcript sequence was assembled with Trinity, and each gene was taken based on the transcript sequence. The longest transcript sequence was recorded as 'Unigene'.
RPKMs (Reads Per Kilobase Million Mapped Reads) [67] were used in DESeq2 [68] to compare the differences of gene expression between the nematodes and sterile water treat. Genes with $\mid \log 2$ Fold Change $\mid \geq 1$ and $\mathrm{q}<0.05$ were selected as significantly DEGs. Then, DEGs were further annotated by Gene Ontology (GO) function (http://www.geneontology.org/).

\section{Identification of immune-related genes in Holotrichia parallela}

To identify the immune-related genes involved in the process of $H$. parallela larvae defence against nematode infection, we query with the terms that are reported as the immune relative genes from the differential gene expression data that obtained above. The terms mainly include 'immune', 'recognition protein', 'haemocyte', 'glutactin', 'antimicrobial', 'lysozyme', 'lipopolysaccharide', 'lectins', 'peptidoglycans' etc. All candidate immune genes were manually verified with the BLASTx program at the National Center for Biotechnology Information (NCBI: https://www.ncbi.nlm.nih.gov/). Thereafter, we focused on immune genes that were significantly induced at both time points, as these potential candidate immune-related genes may be involved in the immune responses to effectively resist nematode infection.

\section{Bioinformatics analysis of three potential candidate immune-related genes}

The deduced amino acid sequences of three potential candidate immune-related genes (PGRP-SC1, PPAE-I and GST) were obtained using the Translate tool provided by the Swiss Institute Bioinformatics (https://web.expasy.org/ translate/). The signal peptide and transmembrane domain were analyzed by SignalP 5.0 (http://www.cbs.dtu. $\mathrm{dk} /$ services/SignalP) and TMHMM server v. 2.0 (http:// www.cbs.dtu.dk/services/TMHMM/). In addition, domain analysis of the retrieved protein sequences were executed by NCBI Conserve-Domain Tool (https://www.ncbi.nlm. nih.gov/cdd) and PROSITE (http://au.expasy.org/prosite/). The 3D structures were obtained using templates of Bumblebee PGRP-SA (5xz4.1.A, 34.76\% identity), Holotrichia diomphalia PPAF-I (2olg.1.A, 66.67\% identity) and Nilaparvata lugens GST S2 (5h5l.1.A, 40.30\% identity), respectively, employing online Swiss-model software. ProCHECK (http://servicesn.mbi.ucla.edu/PROCHECK/) was used to evaluate the rationality of the 3D structure of the constructed model. The generated PDB files were then visualized with Pymol Molecular Graphics System.

Phylogenetic analysis of PGRP-SC1 from $H$. parallela and 53 PGRPs from 12 other insect species; PPAE-I from $H$. parallela and 26 SPs from 12 other insect species; GST from $H$. parallela and 26 GSTs from 12 other insect species, which were used to construct a phylogenetic tree using MEGA5.0. Phylogenetic analysis were 
conducted by the neighbour-joining method with $p$-distance under the default parameters. Bootstrap values were obtained by the bootstrap method using 1000 repetitions. The species name, gene name, abbreviation and GenBank accession involved in phylogenetic analysis are listed in Supplementary Table S3.

\section{Spatiotemporal analysis of PGRP-SC1, PPAE-I and GST}

To determine the expression profiles of these genes in different development stages and tissues, we collected eggs ( 5 days old, $\sim 60 \mathrm{mg}$ ), first instar larvae (10 days old, $\sim 60 \mathrm{mg}$ ), second instar larvae (18 days old), third instar larvae (28 days old) and various tissues (hemolymph, malpighian tubule, midgut and fat body) of the first instar larvae for RNA isolation. Total RNA samples of each treatment were individually extracted using TRIzol Reagent (TIANGEN, Biotech (Beijing) Co., Ltd., China) and each treatment repeat three times. First-strand cDNA was synthesized from $1 \mu \mathrm{g}$ of total RNA following the instructions of TransScript One-Step gDNA Removal and cDNA Synthesis SuperMix (TransGen Biotech (Beijing) Co., Ltd., China). The cDNA products were diluted 10-fold for use as template in qRT-PCR.

qRT-PCR was performed with Tip Green qPCR SuperMix (TransGen, China) on an ABI Prism 7500 Fast Detection System using a GO Taq ${ }^{\circ} \mathrm{qPCR}$ kit (Invitrogen, USA) according to the manufacturer's instructions. Gene-specific primers designed for target genes are listed in Supplementary Table S4. qRT-PCR reactions were performed in a $20 \mu \mathrm{l}$ mixture containing $2 \mu \mathrm{l}$ of cDNA, $10 \mu \mathrm{l}$ of Tip Green qPCR SuperMix, $0.4 \mu \mathrm{l}$ of each primer $(10 \mu \mathrm{M})$, and $7.2 \mu \mathrm{l}$ of nuclease-free water. The optimized qRT-PCR programme conditions were $94{ }^{\circ} \mathrm{C}$ for $30 \mathrm{~s}$ followed by 40 cycles of $94{ }^{\circ} \mathrm{C}$ for $5 \mathrm{~s}$ and $60^{\circ} \mathrm{C}$ for $34 \mathrm{~s}$. After the cycling protocol, melting curves were obtained by increasing the temperature from 60 to $95^{\circ} \mathrm{C}\left(0.2^{\circ} \mathrm{C} \mathrm{sec}^{-1}\right)$ to denature the double-stranded DNA. H. parallela DAPDH was used as an internal standard to normalize the expression level. Each qRTPCR experiment was performed with three biological replicates and four technical replicates. The relative expression level of target genes was calculated with the $2^{-\Delta \Delta \mathrm{Ct}}$ method [69].

\section{qRT-PCR validation}

To confirm the transcriptome results, these immune-related genes (i.e., PGRP-SC1, PPAE-I and GST) of $H$. parallela responding to nematode infection were selected for qRTPCR analysis. Fresh total RNA was obtained as described in RNA-Seq and qRT-PCR was performed as described above.

\section{RNA interference to Holotrichia parallela larvae}

dsRNA synthesis: RNAi was used to study the functions of PGRP-SC1, PPAE-I, and GST involved in the immune defence system of $H$. parallela against $H$. beicherriana LF infection. Specific primers (Supplementary Table S4) with $\mathrm{T} 7$ promoter sequences were designed to synthesize dsRNA of PGRP-SC1, PPAE-I, GST and GFP using the T7 RiboMAX ${ }^{\mathrm{mu}}$ Express RNAi kit (Promega, WI, USA) according to the manufacturer's instructions. The size of the dsRNA products was confirmed by electrophoresis on $1.2 \%$ agarose gel, and the final concentration of dsRNA was adjusted to $1 \mu \mathrm{g} / \mu \mathrm{l}$.

In vivo RNAi: For in vivo RNAi, $1.5 \mu \mathrm{g}$ of each dsRNA, dsGFP and the same volume of RNase-free water were injected into the haemocoel of $H$. parallela second instar larvae (18-20 days old) through the abdomen (WPI microinjection system, USA). After injection, the larvae were kept individually in the holes of six-well bioassay trays and fed germinated wheat seeds. The six-well bioassay trays were transferred into a dark incubator under the following conditions: $25^{\circ} \mathrm{C}$ and $80 \% \mathrm{RH}$. The midgut samples ( $n=3$ for each treatment) from challenged or control groups (dsGFP-injected and water-injected) was collected after treatment for 24,48 and $72 \mathrm{~h}$, respectively, and the experiment was performed with three biological replicates. The qRT-PCR process was executed as described above.

\section{Susceptibility of Holotrichia parallela larvae to Heterorhabditis beicherriana LF after RNAi}

Susceptibility of $H$. parallela larvae to $H$. beicherriana LF after RNAi of PGRP-SC1, PPAE-I and GST was conducted by determining the pathogenicity change of $H$. beicherriana LF on $H$. parallela larvae. After injection following our previous procedures, the larvae (18-20 days old) were kept individually in the holes of six-well bioassay trays, fed germinated wheat seeds and then transferred into a dark incubator as described above. Forty eight hours later, two concentrations (100 and 200 IJs/grub) of $H$. beicherriana LF were added to each hole of six-well bioassay trays, respectively. Each injection treatment consisted of 36 individuals (grub) and the experiment was performed three times. The grub mortality was monitored after $24 \mathrm{~h}$, and the infected grubs were marked as inactive and red.

\section{Statistical analysis}

Data statistics were performed using GraphPad Prism software version 8.0. All proportions were transformed by arcsine square root transformation in Microsoft Excel 5.0 before analysis [70]. The significance levels of spatiotemporal analysis were analyzed using one-way analysis of variance (ANOVA) followed by Tukey significant difference test $(P<0.05)$. The significance levels of in vivo RNAi and white grubs mortality were analyzed using multiple $t$-test at the significance levels set at ${ }^{*} P<0.05$, ${ }^{* *} P<0.01,{ }^{* * * *} P<0.001$, NS, not significant. 


\section{Abbreviations}

AMPs: Antimicrobial peptides; ANOVA: Analysis of variance; APM: Antigen processing machinery; ATP: Adenosine triphosphate; CCOB: Cellular component organization or biogenesis; DEGs: Differentially expressed genes; EPNs: Entomopathogenic nematodes; FB: Fat body; GO: Gene ontology; GST: Glutathione s-transferase; HE: Hemolymph; HSPs: Heat shock protein; IJs: Infective juveniles; IMD: Immune deficiency pathway; LPS: Lipopolysaccharide; MG: Midgut; MT: Malpighian tubule; NCBI: National Center for Biotechnology Information; PAMPs: Pathogen-associated molecular patterns; PGN: Peptidoglycan; PGRP: Peptidoglycan recognition protein; PGRP-SC1: Peptidoglycan recognition protein SC1; PPAE-I: Prophenoloxidase activating enzyme-l; PPICST: Presynaptic process involved in chemical synaptic transmission; PPO: Prophenoloxidase; PRPs: Pattern recognition proteins; PRRs: Pattern recognition receptors; qRTPCR: Quantitative real-time PCR; RH: Relative humidity; RPKMs: Reads Per Kilobase Million Mapped Reads; SOD: Superoxide dismutase; SP: Signal peptide; SPs: Serine proteases; TM: Transmembrane domain

\section{Supplementary Information}

The online version contains supplementary material available at https://doi. org/10.1186/s12864-021-07506-4.

Additional file 1: Table S1. The annotations of PGRP-SC1, PPAE-I and GST. Table S2: The annotations of symbiotic bacteria in the transcriptomes of the Holotrichia parallela larvae postexposure to $\mathrm{H}$. beicherriana LF for $72 \mathrm{~h}$. Table S3. Summary of all species name, gene name, abbreviation and GenBank accession involved in phylogenetic analysis. Table S4. Oligonucleotides used for QRT-PCR and RNAi. The T7 promoter sequence is bolded in RNAi. Fig. S1. Rationality evaluation results of PGRPSC1 (a), PPAE-I (b) and GST (c) 3D model. The red regions (A, B, L) represents the residues in most favoured regions; Bright yellow regions ( $a, b, \mathrm{l}$, p) represents the residues in additional allowed regions; Dark yellow regions $(\sim a, \sim b, \sim 1, \sim p)$ represents the residues in generously allowed regions.

\section{Acknowledgements}

We thank the Annoroad Gene Technology (Beijing) Co. Ltd. (Beijing, China) for the transcriptome sequencing and analysis.

\section{Authors' contributions}

$J Y$ and $\mathrm{KL}$ conceived and designed the experiments. EL, JL and JQ performed the experiments. $\mathrm{EL}, J Y, \mathrm{KL}$ and $\mathrm{HF}$ analysed the data and wrote the manuscript text. IN, YC, WR and XL participated in the data analysis. All authors read and approved the final manuscript.

\section{Funding}

This work was supported by the National Key R\&D Program of China [2017YFE0130400, 2018YFD0201000], and National Natural Science Foundation of China [31572007].

\section{Availability of data and materials}

These sequence data of H. parallela PGRP-SC1, PPAE-I and GST have been submitted to the GenBank databases under accession number DN15104, DN15190 and DN16733, respectively.

\section{Declarations}

\section{Ethics approval and consent to participate}

Animals used in this research were important agricultural pests, therefore approval from any ethics committee or institutional review board was not necessary. No ethics approval was required for the collection or experimentation of the animal used in this study.

\section{Consent for publication}

Not applicable.

\section{Competing interests}

The authors declare that they have no competing interests.

\section{Author details}

${ }^{1}$ State Key Laboratory for Biology of Plant Diseases and Insect Pests, Institute of Plant Protection, Chinese Academy of Agricultural Sciences, Yuanmingyuan West Road, Beijing 100193, China. ${ }^{2}$ Boyce Thompson Institute for Plant Research, Cornell University, 533 Tower Road, Ithaca, NY 14853, USA ${ }^{3}$ College of Life Sciences, Nankai University, Tianjin 300071, P.R. China.

Received: 8 November 2020 Accepted: 4 March 2021

Published online: 17 March 2021

\section{References}

1. Toepfer S, Li HM, Pak SG, Son KM, Ryang YS, Kang SI, Han RC, Holmes K. Soil insect pests of cold temperate zones of East Asia, including DPR Korea: a review. J Pest Sci. 2014;87(4):567-95. https:/doi.org/10.1007/s10340-013-0540-8.

2. Cao YZ, Wu YQ. Soil dwelling insect pests. In: Guo YY, editor. Crop diseases and insects in China. Beijing: China Agriculture Press; 2015. p. 1541-3.

3. Pan Y, Zhao SW, Tang XL, Wang S, Wang X, Zhang XX, Zhou JJ, Xi JH. Transcriptome analysis of maize reveals potential key genes involved in the response to belowground herbivore Holotrichia parallela larvae feeding. Genome. 2020;63(1):1-12. https://doi.org/10.1139/gen-2019-0043.

4. Luo ZX, Li KB, Cao YZ, Yin J, Zhang J, Zhang JH, Shang GQ. Investigations on soil-inhabiting pests in peanut fields in Henan. Plant Prot. 2009;35(2): 104-8.

5. Liu QZ, Li JX, Xu XJ, Sun CM, Kang YG, Zhou HY, Hu DX, Ma J, Li SX. The preliminary study on grub control with Rhabditis (Oscheius) spp in peanut fields. Acta Agric Boreali-Sin. 2007;22(S2):250-3.

6. Pei GY, Ma SF, Liu J, Liu BC. Effects of different cultivation patterns on grubs occurrence and yield in soybean fields. Soybean Bull. 2010;4:19-20.

7. Li ET, Cao YZ, Zhang S, Li KB, Li JY, Wang QL, Liu CQ, Yin J. Bioefficacy of the combined application of entomopathogenic nematode Heterorhabditis beicherriana strain LF and Bacillus thuringiensis strain HBF-18 against Holotrichia oblita (Coleoptera: Scarabaeidae) larvae. Acta Entomol Sin. 2019; 62(5):605-14.

8. Liu SS, Li KB, Yin J, Cao YZ. Review of the researches on biological control of grubs. Chin J Biol Control. 2008;24:168-73.

9. Li ET. Overview of the effectiveness of entomopathogenic nematodes. In: Chen WQ, editor. Green plant protection and rural revitalization. Beijing: China Agricultural Sciences and Technology Press; 2018. p. 184-91.

10. Grewal PS, Ehlers R-U, Shapiro-llan DI. Nematodes as biocontrol agents. In:

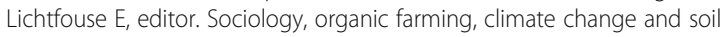
science. Oxfordshire: CABI Press; 2005. p. 347-78.

11. Toepfer S, Kurtz B, Kuhlmann U. Influence of soil on the efficacy of entomopathogenic nematodes in reducing Diabrotica virgifera in maize. J Pest Sci. 2010;83(3):257-64. https://doi.org/10.1007/s10340-010-0293-6.

12. Bal HK, Grewal PS. Lateral dispersal and foraging behavior of entomopathogenic nematodes in the absence and presence of mobile and non-mobile hosts. PLoS One. 2015;10(6):e0129887. https://doi.org/10.1371/ journal.pone.0129887.

13. Toubarro D, Lucena-Robles M, Nascimento G, Costa G, Montiel R, Coelho AV, Simōes N. An apoptosis inducing serine protease secreted by the entomopathogenic nematode Steinernema carpocapsae. Int J Parasitol. 2009; 39(12):1319-30. https://doi.org/10.1016/j.ijpara.2009.04.013.

14. Kaya HK. Entomopathogenic nematodes in biological control. In: Gaugler R, Kaya HK, editors. Soil ecology. Boca Raton: CRC Press; 1990. p. 93-115.

15. Glaser RW, Fox H. A nematode parasite of the Japanese beetle (Popillia japonica Newm.). Science. 1930;71(1827):16-7. https://doi.org/10.1126/ science.71.1827.16-b.

16. Glaser RW, Farrell CC. Field experiments with the Japanese beetle and its nematode parasite. J New York Entomol. 1935;43(3):345-71.

17. Li SC, Ding WD, Han FS. Application of entomophagous nematode Taishan no. 1 against peanut grubs. J Plant Prot. 1993;20:55-60.

18. Koppenhöfer AM, Brown IM, Gaugler R, Grewal PS, Kaya HK, Klein MG. Synergism of entomopathogenic nematodes and imidacloprid against white grubs: greenhouse and field evaluation. Biol Control. 2000;19(3):24551. https://doi.org/10.1006/bcon.2000.0863.

19. Koppenhöfer AM, Fuzy EM. Steinernema scarabaei for the control of white grubs. Biol Control. 2003;28(1):47-59. https://doi.org/10.1016/\$1049-9644(03 )00048-3.

20. Guo WX, Yan X, Zhao GY, Han RC. Efficacy of entomopathogenic Steinernema and Heterorhabditis nematodes against white grubs 
(Coleoptera: Scarabaeidae) in peanut fields. J Econ Entomol. 2013;106(3): 1112-7. https://doi.org/10.1603/EC12477.

21. Guo WX, Yan X. Zhao GY, Chen JH, Han RC. Efficacy of entomopathogenic Steinernema and Heterorhabditis nematodes against Holotrichia oblita. J Pest Sci 2015; 88(2): 359-368, DOI: https:/doi.org/10.1007/s10340-014-0626-y.

22. Shapiro-llan DI, Gouge DH, Koppenhöfer AM. Entomopathogenic nematology. In: Gaugler R, editor. Factor affecting commercial success: Case studies in cotton turf and citrus. Oxfordshire: CABI Press; 2002. p. 333-56.

23. Shapiro-llan DI, Gough DH, Piggott SJ, Patterson JF. Application technology and environmental considerations for use of entomopathogenic nematodes in biological control. Biol Control. 2006;38(1):124-33. https://doi.org/10.1016/ j.biocontrol.2005.09.005.

24. Bang K, Sj H, Lee J, Cho S. Identification of immunity-related genes in the larvae of Protaetia brevitarsis seulensis (Coleoptera: Cetoniidae) by a next-generation sequencing-based transcriptome analysis. J Insect Sci. 2015;15(1):142

25. Castillo JC, Reynolds SE, Eleftherianos I. Insect immune responses to nematode parasites. Trends Parasitol. 2011;27(12):537-47. https://doi.org/1 0.1016/j.pt.2011.09.001.

26. Wang Y, Gaugler R, Cui L. Variations in immune response of Popillia Japonica and Acheta domesticus to Heterorhabditis bacteriophora and Steinernema species. J Nematol. 1994:26(1):11-8.

27. Li X-Y, Cowles RS, Cowles EA, Gaugler R, Cox-Foster DL. Relationship between the successful infection by entomopathogenic nematodes and the host immune response. Int J Parasitol. 2007;37(3-4):365-74. https://doi. org/10.1016/j.jpara.2006.08.009.

28. An R, Voss M, Jagdale GB, Grewal PS. Differences in immune defense evasion of selected inbred lines of Heterorhabditis bacteriophora in two white grub species. Insects. 2012;3(2):378-89. https://doi.org/10.3390/ insects3020378.

29. Janeway CA, Medzhitov R. Innate immune recognition. Annu Rev Immunol. 2002;20(1):197-216. https://doi.org/10.1146/annurev.immunol.20.083001. 084359

30. Steiner H. Peptidoglycan recognition proteins: on and off switches for innate immunity. Immunol Rev. 2004;198(1):83-96. https://doi.org/10.1111/j. 0105-2896.2004.0120.x.

31. Montaño AM, Tsujino F, Takahata N, Satta Y. Evolutionary origin of peptidoglycan recognition proteins in vertebrate innate immune system. BMC Evol Biol. 2011;11(1):79. https://doi.org/10.1186/1471-2148-11-79.

32. Dziarski R, Gupta D. How innate immunity proteins kill bacteria and why they are not prone to resistance. Curr Genet. 2018;64(1):125-9. https://doi. org/10.1007/s00294-017-0737-0

33. Cerenius $L$, Söderhäll $K$. The prophenoloxidase activating system in vertebrates. Immunol Rev. 2004;198(1):116-26. https://doi.org/10.1111/j.01 05-2896.2004.00116.x.

34. Bang K, Park S, Yoo JY, Cho S. Characterization and expression of attacin, an antibacterial protein-encoding gene, from the beet armyworm, Spodoptera exigua (Hübner) (Insecta: Lepidoptera: Noctuidae). Mol Biol Rep. 2012;39(5): 5151-9. https://doi.org/10.1007/s11033-011-1311-3.

35. Kwon HJ, Bang K, Lee M, Cho S. Molecular cloning and characterization of a lysozyme cDNA from the mole cricket Gryllotalpa orientalis (Orthoptera: Gryllotalpidae). Mol Biol Rep. 2014;41(9):5745-54. https://doi.org/10.1007/s11 033-014-3446-5.

36. Liu Y, Shen DX, Zhou F, Wang GR, An CJ. Identification of immunity-related genes in Ostrinia furnacalis against entomopathogenic fungi by RNA-seq analysis. PLoS One. 2014;9(1):e86436. https://doi.org/10.1371/journal.pone. 0086436.

37. Vogel H, Badapanda C, Knorr E, Vilcinskas A. RNA-sequencing analysis reveals abundant developmental stage-specific and immunity-related genes in the pollen beetle Meligethes aeneus. Insect Mol Biol. 2014;23(1):98-112. https://doi.org/10.1111/imb.12067.

38. Arefin B, Kucerova L, Dobes P, Markus R, Strnad H, Wang Z, Hyrsl P, Zurovec M, Theopold U. Genome-wide transcriptional analysis of Drosophila larvae infected by entomopathogenic nematodes shows involvement of complement, recognition and extracellular matrix proteins. J Innate Immun. 2014;6(2):192-204. https://doi.org/10.1159/000353734.

39. An R, Suri KS, Jurat-Fuentes JL, Grewal PS. Dynamics of transcriptomic response to infection by the nematode Heterorhabditis bacteriophora and its bacterial symbiont Photorhabdus temperata in Heliothis virescens larvae. Insect Mol Biol. 2017;26(5):584-600. https://doi.org/10.1111/imb.12321.

40. Dziarski R, Gupta D. The peptidoglycan recognition proteins (PGRPs). Genome Biol. 2006;7(8):232. https://doi.org/10.1186/gb-2006-7-8-232.
41. Zou Z, Shin SW, Alvarez KS, Kokoza V, Raikhel AS. Distinct melanization pathways in the mosquito Aedes aegypti. Immun. 2010;32(1):41-53. https:// doi.org/10.1016/j.immuni.2009.11.011.

42. Wang CY, Zhao JM, Mu CK, Wang Q, Wu HF, Wang CL. CDNA cloning and mRNA expression of four glutathione s-transferase (GST) genes from Mytilus galloprovincialis. Fish Shellfish Immun. 2013;34(20):697e703.

43. Wu SH, Roger R, Loke TK, Curt AL, Douglas GP. Interaction between entomopathogenic nematodes and entomopathogenic fungi applied to third instar southern masked chafer white grubs, Cyclocephala lurida (Coleoptera: Scarabaeidae), under laboratory and greenhouse conditions. Biol Control. 2014;76:65-73. https://doi.org/10.1016/j.biocontrol.2014.05.002.

44. Wang Y, Campbell JF, Gaugler R. Infection of entomopathogenic nematodes Steinernema glaseri and Heterorhabditis bacteriophora against Popillia japonica (Coleoptera, Scarabaeidae) larvae. J Invertebr Pathol. 1995; 66(2):178-84. https://doi.org/10.1006/jipa.1995.1081.

45. Bowen D, Rocheleau TA, Blackburn M, Andreev O, Golubeva E, Bhartia R, Ffrench-Constant RH. Insecticidal toxins from the bacterium Photorhabdus luminescens. Science. 1998;280(5372):2129-32. https://doi.org/10.1126/ science.280.5372.2129.

46. Stokes BA, Yadav S, Shokal U, Smith LC, Eleftherianos I. Bacterial and fungal pattern recognition receptors in homologous innate signaling pathways of insects and mammals. Front Microbiol. 2015;6:1-12.

47. Meng Q, Zhang JH, Zhang H, Zhou GL, Ni RY, Zhao YN, Qin QL, Zou Z. Comparative analysis of C-type lectin domain proteins in the ghost moth, Thitarodes xiaojinensis (Lepidoptera: Hepialidae). Insect Sci. 2019;26(3):45365. https://doi.org/10.1111/1744-7917.12564.

48. Sumathipala N, Jiang HB. Involvement of Manduca sexta peptidoglycan recognition protein-1 in the recognition of bacteria and activation of prophenoloxidase system. Insect Biochem Molec. 2010;40(6):487-95. https:// doi.org/10.1016/j.ibmb.2010.04.008.

49. Xia XF, You MS, Rao XJ, Yu XQ. Insect C-type lectins in innate immunity. Dev Comp Immunol. 2018;83:70-9. https://doi.org/10.1016/j.dci.2017.11.020.

50. Zhou J, Zhao LL, Yu HY, Zhang W, Ahmad F, Hu SN, Zou Z, Sun JH. Comparative analysis of the Monochamus alternatus immune system. Insect Sci. 2018;25(4):581-603. https://doi.org/10.1111/1744-7917.12453.

51. Zaidman-Rémy A, Hervé M, Poidevin M, Pili-Floury S, Kim MS, Blanot D, Oh BH, Ueda R, Mengin-Lecreulx D, Lemaitre B. The Drosophila amidase PGRPLB modulates the immune response to bacterial infection. Immunity. 2006; 24(4):463-73. https://doi.org/10.1016/j.immuni.2006.02.012.

52. Kurata S. Peptidoglycan recognition proteins in Drosophila immunity. Dev Comp Immunol. 2014;42(1):36-41. https://doi.org/10.1016/j.dci.2013.06.006.

53. Schmidt RL, Trejo TR, Plummer TB, Platt JL, Tang AH. Infection-induced proteolysis of PGRP-LC controls the IMD activation and melanization cascades in Drosophila. FASEB J. 2008;22(3):918-29. https://doi.org/10.1096/fj. 06-7907com.

54. Zhan MY, Yang PJ, Rao XJ. Molecular cloning and analysis of PGRP-L1 and IMD from silkworm Bombyx mori. Comp Biochem Phys B. 2018;215:19-30. https://doi.org/10.1016/j.cbpb.2017.10.002.

55. Chu Y, Liu Y, Shen DX, Hong F, Wang GR, An CJ. Serine proteases SP1 and SP13 mediate the melanization response of Asian corn borer, Ostrinia furnacalis, against entomopathogenic fungus Beauveria bassiana. J Invertebr Pathol. 2015;128:64-72. https://doi.org/10.1016/j.jip.2015.02.010.

56. Kambris Z, Brun S, Jang $\mathbb{H}$, Nam HJ, Romeo Y, Takahashi K. Drosophila immunity: a large-scale in vivo RNAi screen identifies five serine proteases required for toll activation. Curr Biol. 2006;16(8):808-13. https://doi.org/10.1 016/j.cub.2006.03.020.

57. Roh KB, Kim CH, Lee H, Kwon HM, Park JW, Ryu JH, Kurokawa K, Ha NC, Lee WJ, Lemaitre B, Söderhäll K, Lee BL. Proteolytic cascade for the activation of the insect toll pathway induced by the fungal cell wall component. J Biol Chem. 2009;284(29):19474-81. https://doi.org/10.1074/jbc.M109.007419.

58. Lee SY, Kwon TH, Hyun JH, Choi JS, Kawabata S, Iwanaga S, Lee BL. In vitro activation of prophenoloxidase by two kinds of pro-phenol oxidase activating factors isolated from hemolymph of coleopteran, Holotrichia diomphalia larvae. Eur J Biochem. 1998;254(1):50-7. https://doi.org/10.1046/ j.1432-1327.1998.2540050.x.

59. Liu CY, Song YY, Ren HN, Sun GG, Liu RD, Jiang P, Long SR, Zhang X, Wang ZQ, Cui J. Cloning and expression of a Trichinella spiralis putative glutathione stransferase and its elicited protective immunity against challenge infections. Parasite Vector. 2017;10(1):448. https://doi.org/10.1186/s13071-017-2384-1.

60. Feng QL, Davey KG, Pang ASD, Primavera M, Ladd TR, Zheng SC, Sohi SS, Retnakaran A, Palli SR. Glutathione s-transferase from the spruce bud worm, 
Choristoneura fumiferana: identification, characterization, localization, cDNA cloning, and expression. Insect Biochem Molec. 1999;29(9):779-93. https:// doi.org/10.1016/S0965-1748(99)00048-X.

61. Ketterman AJ, Saisawang C, Wongsantichon J. Insect glutathione transferases. Drug Metab Rev. 2011;43(2):253-65. https://doi.org/10.3109/03 602532.2011.552911.

62. Altincicek B, Elashry A, Guz N, Grundle FA, Vilcinskas A, Dehne HW. Next generation sequencing based transcriptome analysis of septic-injury responsive genes in the beetle Tribolium castaneum. PLoS One. 2013;8: e52004.

63. Lemaitre B, Hoffmann J. The host defense of Drosophila melanogaster. Annu Rev Immunol. 2007;25(1):697-743. https://doi.org/10.1146/annurev. immunol.25.022106.141615.

64. Vogel H, Badapanda C, Knorr E, Vilcinskas A. Identifification of immunityrelated genes in the burying beetle Nicrophorus vespilloides by suppression subtractive hybridization. Insect Mol Biol. 2011;20(6):787-800. https://doi. org/10.1111/j.1365-2583.2011.01109.x.

65. Malan AP, Konetze R, Moore SD. Isolation and identification of entomopathogenic nematodes from citrus orchards in South Africa and their biocontrol potential against false codling moth. J Invertebr Pathol. 2011;108(2):115-25. https://doi.org/10.1016/j.jip.2011.07.006.

66. Grabherr MG, Haas BJ, Yassour M, Levin J, Thompson DA, Amit I, et al. Fulllength transcriptome assembly from RNA-seq data without a reference genome. Nat Biotechnol. 2011;29(7):644-52. https://doi.org/10.1038/nbt.1883.

67. Mortazavi A, Williams BA, McCue K, Schaeffer L, Wold B. Mapping and quantifying mammalian transcriptomes by RNA-seq. Nat Methods. 2008;5(7): 621-8. https://doi.org/10.1038/nmeth.1226.

68. Anders $\mathrm{S}$, Huber W. Differential expression analysis for sequence count data. Genome Biol. 2010;11(10):R106. https://doi.org/10.1186/gb-2010-11-10-r106.

69. Livak KJ, Schmittgen TD. Analysis of relative gene expression data using real-time quantitative PCR and the 2(-Delta Delta C(T)) method. Methods. 2001;25(4):402-8. https://doi.org/10.1006/meth.2001.1262.

70. Abbott WS. A method of computing the effectiveness of an insecticide. J Econ Entomol. 1925;18(2):265-7. https://doi.org/10.1093/jee/18.2.265a.

\section{Publisher's Note}

Springer Nature remains neutral with regard to jurisdictional claims in published maps and institutional affiliations.

Ready to submit your research? Choose BMC and benefit from:

- fast, convenient online submission

- thorough peer review by experienced researchers in your field

- rapid publication on acceptance

- support for research data, including large and complex data types

- gold Open Access which fosters wider collaboration and increased citations

- maximum visibility for your research: over $100 \mathrm{M}$ website views per year

At $\mathrm{BMC}$, research is always in progress.

Learn more biomedcentral.com/submissions 